\title{
Internet Exchanges for Used Goods: An Empirical Analysis of Trade Patterns and Adverse Selection $^{1}$
}

\author{
Anindya Ghose \\ Leonard Stern School of Business \\ New York University \\ E-mail: aghose@stern.nyu.edu
}

\begin{abstract}
The past few years have witnessed the increasing ubiquity of user-generated content on seller reputation and product condition in Internet based used-good markets. Recent theoretical models of trading and sorting in used-good markets provide testable predictions to use to examine the presence of adverse selection and trade patterns in such dynamic markets. A key aspect of such empirical analyses is to distinguish between product-level uncertainty and seller-level uncertainty, an aspect the extant literature has largely ignored. Based on a unique, 5-month panel dataset of user-generated content on used good quality and seller reputation feedback collected from Amazon, this paper examines trade patterns in online used-good markets across four product categories (PDAs, digital cameras, audio players, and laptops). Drawing on two different empirical tests and using content analysis to mine the textual feedback of seller reputations, the paper provides evidence that adverse selection continues to exist in online markets. First, it is shown that after controlling for price and other product and seller-related factors, higher quality goods take a longer time to sell compared to lower quality goods. Second, this result also holds when the relationship between sellers' reputation scores and time to sell is examined. Third, it is shown that price declines are larger for more unreliable products, and that products with higher levels of intrinsic unreliability exhibit a more negative relationship between price decline and volume of used good trade. Together, our findings suggest that despite the presence of signaling mechanisms such as reputation feedback and product condition disclosures, the information asymmetry problem between buyers and sellers persists in online markets due to both productbased and seller-based information uncertainty. No consistent evidence of substitution or complementarity effects between product-based and seller-level uncertainty are found. Implications for research and practice are discussed.
\end{abstract}

Keywords: Information uncertainty, adverse selection, user-generated content, text analysis, seller reputation, product quality, used goods, electronic markets, information asymmetry, trade patterns.

\footnotetext{
${ }^{1}$ I wish to thank the Senior Editor, Bernard Tan, the Associate Editor and two anonymous referees for very helpful suggestions. Many colleagues, particularly Christina Aperjis, Sanjeev Dewan, Chris Forman, Jeremy Fox, Bin Gu, Julia Haerring, Panagiotis Ipeirtois, Greg Lewis, Paul Pavlou, Roy Radner, and participants at INFORMS 2005, the NET Institute 2006 conference, NYU Stern School of Business and the ZEW 2006 Workshop on ICT provided helpful comments on earlier versions of the paper. I also thank Shawndra Hill, Ashley Tyrell, and Rong Zheng for excellent research assistance. I wish to acknowledge the generous financial support of the National Science Foundation through CAREER Award IIS-0643847. Support was also provided by a grant from the NET Institute and NYU Research Challenge Fund. The usual disclaimer applies.
} 


\section{INTRODUCTION}

Internet based used-good markets, e.g., Amazon and E-Bay, reduce search and transaction costs for buyers and sellers and facilitate product exchanges that would not be viable in a comparable brick-and-mortar environment (Ghose et al. 2006). IT-based artifacts play a key role in making these online markets work. Examples include reputation systems that highlight buyer-generated feedback on transactions (Dellarocas 2003, Ghose et al. 2005, 2007) and product diagnostic tools that highlight seller-generated content on product condition disclosures (Jiang and Benbasat 2007).

In traditional offline retailing, buyers can predict the outcome of a transaction by assessing the seller and the product characteristics in a deterministic manner. However, in online used-good markets such characteristics cannot always be reliably described or verified prior to a transaction. While attributes such as product features can be communicated easily in electronic markets, "non-digital” attributes, such as product condition and seller integrity, are subject to noise and manipulation, producing an information asymmetry problem for electronic markets. This information asymmetry can lead to adverse selection and moral hazard problems (Akerlof 1970) and is often associated with uncertainty from two sources: A seller's personal characteristics, such as seller quality; and secondly, a product's attributes, such as condition of the used-product. $^{2}$

User-generated feedback posted in seller reputation profiles contains buyer assessments of these characteristics. These assessments can potentially augment the richness of information in the composite numerical reputation scores (Ghose et al. 2005, 2007) and alleviate information uncertainty. However, this proposition remains to be empirically tested. Our study considers the two sources of uncertainty and their relationship to trade patterns, such as sale time and price decline of used goods, and then explores whether adverse selection occurs in online used-good markets. This becomes important since the viability of Internet-based, used-good exchanges is likely to hinge on whether non-technological, but fundamentally economic, issues like adverse selection are identified and addressed.

Uncertainty about seller quality can arise from risks involved in the transaction, such as failure to deliver on time, an error in shipping the right product, or intentionally misrepresenting the product (Ghose et al 2005, Pavlou et al. 2006, Ghose et al. 2007). The nature of online exchanges generally prevents buyers from using social cues (e.g., physical interaction and body

\footnotetext{
${ }^{2}$ Adverse selection can arise from pre-contractual misrepresentation of the seller's true attributes and offering of false product information. Moral hazard can arise from the seller's post-contractual shirking, contract default, fraud or reducing the promised quality of product offerings (Pavlou et al. 2006). In this paper, we only examine adverse selection.
} 
language) to assess seller quality (Gefen et al. 2003). Uncertainty about product condition can arise when buyers cannot physically evaluate a product until after delivery and payment. The buyer must, therefore, rely on the seller's self-reported product condition to assess quality, knowing that the seller may not disclose the true condition of the used good. This is particularly true for used electronics products since their quality cannot be fully assessed before purchase.

The presence of this information asymmetry leads to a "lemons" problem where lowquality goods drive out high-quality goods in static markets (Akerlof 1970). Basically, if true quality is not observable at the time of transaction, sellers of high quality goods have little incentive to transact at discounted prices that reflect the average quality of goods traded. As sellers with high-quality goods leave the market, both price and average quality spiral downward, leaving only the "lemons". Consequently, when valuation depends on quality of goods and the market is static, market failure manifests itself by higher quality goods not being traded despite the potential gains from such a trade. User-generated reputation feedback, therefore, plays a vital role in influencing economic exchanges by shedding light on the various dimensions of a seller's historical performance in the same market (Ghose et al 2005, Pavlou and Dimoka 2006, Ghose et al. 2007).

Despite the existence of seller and product quality uncertainties, the prior literature has primarily focused on the effect of seller quality uncertainty through examining reputation ratings and user-generated textual feedback (Dellarocas 2003, Ghose et al. 2005, Pavlou and Dimoka 2006, Ghose et al. 2007). Since the intermediary hosting the online market does not always guarantee these characteristics, these markets rely on reputation systems to substitute for the protocols that one takes for granted in face-to-face transactions. Some of the prior research has examined perceived diagnosticity, which allows easier product evaluation in electronic shopping (Jiang and Benbasat 2007). However, research on highlighting how product condition affects information uncertainty in online markets is nascent. We argue here that product condition uncertainty is an equally important feature of these electronic markets, and its impact needs to be explicitly measured and analyzed in conjunction with seller quality uncertainty. This paper contributes to the emerging stream of work that highlights product-level uncertainty in online markets, such as that of Dimoka and Pavlou (2008). Their paper reveals the stronger impact of product uncertainty on price premiums and sales, compared to seller uncertainty and highlights the important product information signals in the used car market. In contrast, our paper focuses on sale time and trade volumes for used electronic goods to reveal that seller-level and product-level uncertainty together affect trading patterns.

Prior work has focused on the effect of price as a sorting mechanism in markets characterized by information asymmetry. Recent theoretical work (Janssen and Karamychev 
2002, Blouin 2003, Janssen and Roy 2004) indicate that sale time plays an important role in sorting the effects of information uncertainty in such markets. In a static market, low quality goods drive out high quality goods through adverse selection (Akerlof 1970). However, in a dynamic market with entry and exit by buyers and sellers, the outcome can be quite different. In such markets, the "lemons problem" caused by adverse selection is not about the impossibility of trading high quality goods, but rather that sellers of higher quality goods need to wait and, wait longer to complete a trade than sellers with lower quality goods. The welfare loss from waiting in such markets is the main index of market failure caused by asymmetric information (Janssen and Roy 2004).

In sum, our main objective is to test for the presence of adverse selection in online exchanges for used goods, using an analysis of buyer-generated content about sellers and sellergenerated content about products. We proceed in two ways. First, we examine the relationship between sale time and product condition as well as sale time and seller reputation to test if higher quality goods and higher reputation sellers take a longer time to sell than others. Second, we investigate trade patterns, such as the volume of the used good traded and the residual price of the used good as a function of the intrinsic reliability of the brand. We control for indirect quality indicators embedded in user-generated feedback on seller reputation, used-good condition, and sale price. The analyses shed light on the extent of adverse selection in such markets (Gilligan 2004) to corroborate the results from the first analysis.

Evidence of the insights in Akerlof's (1970) seminal work is mixed in contemporary durable goods markets. Bond (1984) finds weak evidence of adverse selection among older trucks only. Lacko (1986) analyzes the distribution of repair costs for used cars bought through a variety of channels and finds that for cars that are less than seven years old, the distribution of repair costs is similar for all used cars. Both Bond (1984) and Lacko (1986) determined that as vehicles get older, the quality of vehicles sold in the used market becomes lower. Genesove (1993) then discovers only slight evidence of adverse selection in dealer auction markets for used cars. Studies using data from electronic markets have also produced mixed results. Garicano and Kaplan (2001) analyze the wholesale automotive market and conclude that this electronic market was not affected by adverse selection because of safeguarding policies implemented by the market-maker. In contrast, Fabel and Lehmann (2000), and Emons and Sheldon (2002) find stronger support for the existence of adverse selection in the used automobile markets on the Internet. Dewan and Hsu (2004) find evidence of adverse selection on eBay in their analysis of collectible stamps. Using data for sales of Corvettes on eBay, Adams et al. (2005) do not find empirical support for adverse selection. Conversely, Wolf and Muhanna (2005) do find some evidence in the context of used cars; newer cars and cars with low mileage are less likely to sell on eBay. Lewis (2007) then finds 
that seller disclosures through online media tools can reduce adverse selection problems for used cars on eBay. Overby (2008) further finds that there is adverse selection for used cars in the physical market, which is dependent on product type.

While these prior studies primarily focus on auctions of stamps and automobiles, our study is based on a panel dataset that contains a wide variety of electronics goods sold through posted prices on Amazon. The data reflects a five-month period from February to July 2005 from Amazon.com. The products included laptops, PDAs, digital cameras, and audio players. The sample set within each product category consists of fairly homogenous goods, similar in features and manufacturer brand reputation when new. However, once used, these items become heterogeneous due to a disparity in used-product condition and diversity in seller reputation profiles. These aspects allow us to isolate the impact of the two sources of uncertainty that are inherent in such online markets: seller-specific and product-specific characteristics.

To summarize, three key differences differentiate this paper from the existing empirical work on adverse selection. First, prior work primarily focuses on theories of adverse selection in static markets where price is a sorting mechanism. In contrast, our paper tests the theory in the recent literature on dynamic markets (Janssen and Karamychev 2002, Blouin 2003, Janssen and Roy 2004) where time is a sorting mechanism in addition to price. The basic idea of time-based sorting is that sellers face a tradeoff between making a quick sale and obtaining a high price. High-quality sellers resolve this issue by setting a higher-than-average price and waiting longer on the market. In the end, all goods are traded, but high-quality goods sell with a delay. Second, the emphasis in the prior work is primarily on information uncertainty due to seller reputation (see Dellarocas 2003 for a review). In contrast, we investigate the impact of both product condition and seller reputation induced information asymmetry. Third, our paper examines trade patterns and adverse selection using data from electronic used-good markets where product prices are posted, unlike online auctions where buyer valuations and other auction characteristics (such as the reserve auction format, relative opening price, and number of bids) play an explicit role in determining successful bids (Gilkeson and Reynolds 2007). Our setting thus allows a relatively cleaner examination of how seller characteristics affect trade patterns in markets with adverse selection. Because durable goods also have different price decline rates, we are able to identify the effect of adverse selection based on theoretical predictions from prior work that associate price declines with trade volumes for brands with varying reliability (Hendel and Lizzeri 1999).

In the next section, we present the theoretical framework on which the hypotheses are formulated. The data and the different variables used in the empirical analysis are then described in the following section. Thereafter, we present the empirical methodology for testing the various hypotheses and discuss the empirical evidence. Finally, we present a summary of the 
contributions of the study and discuss managerial implications as well as limitations. The final section concludes the discussion.

\section{THEORY AND HYPOTHESES}

\subsection{Sale Time and Product Uncertainty}

The prior literature has shown that in a dynamic market for durable goods wherein goods are continuously traded, there exist equilibria where all sellers, no matter how high the quality of their good, may be able to trade in finite time (Stolyarov 2002, Janssen and Roy 2004, Janssen and Karamychev 2002, Blouin 2003). Although certain indicators like the seller's self-reported product quality and seller reputation ratings are available to buyers, information asymmetries are likely to persist in electronic markets because buyers and sellers are separated by time and space. In such used-good markets, uncertainty caused by asymmetric information manifests itself by sellers' with relatively high quality goods needing to wait longer than sellers with low quality goods to successfully complete a trade. Even though all goods are traded, market failure arises as future gains from the trade are discounted (Janssen and Roy 2004).

The market described by Akerlof (1970) involves centralized trade, wherein a large number of agents exist on both sides of the market, and all agents have simultaneous access to the same trading opportunities. In contrast, trade can also be decentralized, when a market is created by the random matching of agents in pairs. Such a situation describes the market for online used, durable good markets, among others (Nagler and Osgood 2006). When used-good trade is decentralized, (i) all transactions need not occur at the same price, and (ii) both price and time are adjustment mechanisms (Blouin 2003). The intuition is as follows: The seller in a decentralized market faces a tradeoff between quoting a high price vs. quoting a low price. If the seller quotes a high price and sells the item, he or she will garner a greater profit, but may have to wait longer for the good to sell in the first place. On the other hand, quoting a low price may lead to a quicker sale but with a lower profit.

How a seller responds to this tradeoff depends on the reservation price, which in turn depends on the quality of the good being sold. Therefore, sellers with high-quality and lowquality products, despite possibly having the same discount factor, do not account for time in the same way. High-quality good sellers will wait longer to get a higher price. At the market level, this phenomenon exhibits itself by low-quality goods' selling earlier than high-quality goods even after controlling for price (Janssen and Karamychev 2002, Janssen and Roy 2004). The natural outcome is an accumulation of high quality good sellers in the marketplace, relative to low quality good sellers. 
This basic intuition is quite robust across different modeling specifications. Inderst and Muller (2003) consider a used market for durable goods where sellers have private information about the good's quality. In contrast to the standard (static) analysis, these authors show that equilibrium goods of different qualities sell at different prices, with higher quality goods circulating longer than lower quality goods. Other studies, such as those by Janssen and Karamychev (2002) and Janssen and Roy (2004) have shown that this phenomenon occurs even in centralized markets when the good is durable.

In the context of durable goods, such as electronic products, what drives sellers with high quality goods to quote a higher price is the residual (use) value of the good as well as its exchange (or trade) value. Essentially the key concept in the prior work has been that durable goods have a use value in every period in which the good is owned (Janssen and Karamychev 2002, Blouin 2003, Janssen and Roy 2004). The utility to the sellers' holding on to the used good while it is waiting to be sold increases its residual value. Hence, sellers with high quality goods are willing to list that good at a higher price, whereas low quality good sellers have less incentive to wait before selling the good (due to its lower use value). On the other hand, buyers are interested in buying the used-good because their utility from that purchase exceeds the reservation value of the seller. In sum, the circulation time of a used good, that is, the time it takes for a used good to sell after being listed, performs the role of a sorting mechanism in markets characterized by information asymmetries. We expect to see the sale time of a used product vary with its condition. Thus, we offer the following hypothesis:

\section{H1 (Sale Time and Product Uncertainty): All else equal, higher quality goods take a longer time to sell than do lower quality goods in a used-good market.}

\subsection{Sale Time and Seller Uncertainty}

Besides a product's condition, the intrinsic capability of a seller to fulfill contractual obligations during a transaction also affects buyer perception of the overall quality. However, sellers in an electronic market differ widely in their ability and integrity when honoring a contract. This knowledge is typically private information that is known to sellers and unknown to buyers. To alleviate this information asymmetry, buyers use the information contained in a seller's reputation profile to estimate their expected utility from the transaction. Reputation systems are designed to build trust and minimize risk, thus minimizing the adverse effects of information asymmetry between buyers and sellers ( $\mathrm{Ba}$ and Pavlou 2002). A greater number of feedback postings, however, typically suggests a relatively more experienced seller. Further, a higher number of positive scores and a lower number of negative scores signal a high quality seller. This 
aspect can increase a buyer's perceived sense of familiarity and create a level of trust that facilitates a transaction between two strangers (Resnick et al. 2006).

There is an emerging stream of literature that documents evidence of a growing market for reputation feedback manipulation in electronic commerce. Brown and Morgan (2006) show that users on eBay artificially boost their reputations by selling items for very low prices in exchange for positive feedback from the buyer. Such blatant manipulation of reputation information can decrease user trust and credibility for these indicators. Bolton et al. (2004) show that while the feedback mechanism induces quite a substantial improvement in transaction efficiency, the mechanism also presents a kind of public goods problem in that the benefits of trustworthy behavior are not completely internalized, resulting in persistent moral hazard problems.

Reichling (2004) demonstrate empirically that eBay’s feedback system documents successful transactions, but often fails to inform users of unsuccessful ones. Specifically, the timing of feedback indicates that users sometimes withhold feedback to retaliate against any negative feedback they may receive, with the result that some low quality transactions will get positive feedback. Yamagishi and Matsuda (2004) also argue that the effectiveness of online reputation systems to contain the lemon problem is compromised because dishonest sellers can move to alternate e-markets without paying any major entry or exit costs. Indeed, an existing stream of research argues that current online reputation systems are unable to completely alleviate the information asymmetry problem due to the presence of feedback spamming and manipulation. Buyers are unable to reliably parse between lower reputation and higher reputation sellers, leading to a decrease in perceived average reputation scores in the market.

This intuition is similar to the decrease in average product quality perceived by buyers in markets with adverse selection (Akerlof 1970). In such scenarios, higher reputation sellers will take a longer time to sell their products than will lower reputation sellers after controlling for all other factors, such as sale price and product condition. In other words, we expect to see sellers with higher reputation (measured in terms of average reputation scores or proportion of positive feedback postings) have to wait longer than sellers with lower reputation in a market with adverse selection. Thus, we have the following two hypotheses:

H2a (Sale Time and Seller Uncertainty): All else equal, sellers with a lower reputation score will take less time to sell compared to sellers with a higher reputation score in a used-good market.

H2b (Sale Time and Seller Uncertainty): All else equal, sellers with a higher proportion of positive(negative) feedback postings will take more(less) time to sell compared to sellers with a lower proportion of positive(negative) feedback in a used-good market. 


\subsection{Price Decline, Product Reliability, and Trade Volume}

Recent theoretical work (Hendel and Lizzeri 1999) showed that asymmetric information about quality is reflected in quality degradation rates and volume of trade of used products. Two key variables that determine the volume of trade in a used-good market are: (i) the difference between the price of the new and used good - the durable good's price decline, and (ii) the proportion of units of a particular type of durable good traded in the used market - the good's volume of trade. Hendel and Lizzeri (1999) then established the relationship between these two variables under alternative scenarios for the distribution of information in the used, durable goods market. They pointed out that depreciation and adverse selection lead to countervailing effects on trade volume. A more closely related work is Gilligan's (2004) who determined an inverse relationship between price decline and trading volume, in this instance for less reliable brands of used aircraft models.

Hendel and Lizzeri (1999) studied two phenomena that affect the distribution of products traded in a used-good market. The first phenomenon is efficient sorting, where used vehicles, the conditions of which have deteriorated since purchase, are sold to consumers who value the used product more highly. This process is driven by the gains from trade that arise due to heterogeneity in consumer tastes for the used good's condition. The second phenomenon is adverse selection and is driven by uncertainty about the quality of the used product among buyers.

Both Hendel and Lizzeri (1999) and Gilligan (2004) describe the intuition driving these two phenomena by presenting a similar example. Under complete information, buyers and sellers of used durable goods are symmetrically informed about quality. When product quality deterioration is small, some consumers will retain ownership of their used good, rather than incurring the transaction costs associated with trade. When quality deterioration is large, relative to the transaction costs of trading, more consumers will wish to sell their used good and purchase a new good in the current period. Thus, durable good's volume of trade is directly related to quality degradation. Under these circumstances, the price decline is larger and the volume of trade is greater for the brand that deteriorates faster. In other words, if the brand whose price deteriorates faster has a larger volume of trade, then a steeper price decline is explained by depreciation induced efficient sorting. ${ }^{3}$

\footnotetext{
${ }^{3}$ Intuitively, consumers who buy new cars have higher valuations for product quality; hence, such consumers replace cars that deteriorate quickly more frequently. This phenomenon is also empirically corroborated by Porter and Sattler (1999) and Stolyarov (2002) who show that goods that depreciate faster as reflected by a steeper price decline in the used good price have higher trade volumes in a market with perfect information (no information asymmetry). Using the prediction from Hendel and Lizzeri (1999), namely, that adverse selection and efficient sorting both increase the rate of price depreciation, Schneider (2006) considers their joint effect to be an upper bound on the effect of adverse selection in used car markets.
} 
Hendel and Lizzeri (1999) also explain how adverse selection can be caused by incomplete information between buyers and sellers. Since sellers receive a price that is consistent with average unobserved condition in a market with imperfect information, owners of higher quality products would receive lower prices, while owners of lower quality products would receive higher prices than when buyers have perfect information. Consequently, incentives resulting from these price disparities affect the trade volumes and qualities of the vehicles (how reliable they are) that do trade. With asymmetric information, the true quality of the used durable good is known only to the seller, not to potential buyers. Intuitively, when uncertainty about durable good quality is large, a higher proportion of users will retain their used goods rather than sell them at a price equal to the average quality of that specific used good. Hence, price declines are larger, and volumes of trade are lower in this instance than in situations where used good quality can be precisely determined by buyers (Gilligan 2004).

In sum, Hendel and Lizzeri (1999) show that if a brand with a steeper price decline has a lower volume of trade, this aspect is evidence of adverse selection. Similarly, Gilligan (2004) demonstrates that when there is asymmetric information in the market, price declines and trading volumes are inversely related. That relationship becomes stronger with an increase in the unreliability of the brand. Basically, since adverse selection is predicted to decrease the number of high quality products in the distribution of traded products, those products with lower intrinsic reliability (leading to more information asymmetry) will have even lower volumes of trade and increases in price declines (Schneider 2006). The next hypothesis tests for the presence of adverse selection in electronic markets. We expect to see the price decline of a used product vary directly with its unreliability and increasing unreliability to reinforce the negative relationship between price decline and trade volume. Thus, we have the following hypotheses:

\section{H3a (Price Decline and Product Reliability): All else equal, in the presence of adverse selection, an increase in unreliability is associated with an increase in price decline of the product.}

H3b (Price Decline, Trade Volume, and Product Reliability): All else equal, in the presence of adverse selection, there is an inverse relationship between price decline and volume of trade for more unreliable products.

\section{DATA}

To test the hypotheses presented above, we compile a market-level data set for a crosssection of used good sellers from four different categories. This data was compiled from publicly 
available information for used product listings at Amazon, using automated Java scripts to access and parse HTML and XML pages downloaded from the retailer. The data accrued from the 5month period from February to July in 2005. The dataset consists of four kinds of electronic goods, including laptops, digital cameras, audio players, and PDAs (Personal Digital Assistants) available and sold regularly on the used marketplace at Amazon. A detailed description of the variables constructed from the dataset and deployed in the empirical models is given in Table 1. For each of these four categories, our sample set consists of unique products that were a mix of best-selling products (based on Amazon popularity rankings) and randomly selected products. The selection of random goods was done across the major brands in each category to ensure a representative sample of those products and to ensure that we did not have an over-representation of reliable or unreliable brands in each category. Specifically, the dataset has 122 models of PDAs, 177 models of digital cameras, 162 models of audio players and 242 laptop models, but sales during the period of our data were concentrated in a fraction of these products.

Product Characteristics: These electronics products provided a robust environment to test theories of information asymmetry because of the high number of "high quality" electronic goods sold on the used-good market and helped us disentangle the impact of inherent product reliability from the natural usage-based quality degradation of the durable good. From the secondary (used-good) market for each product, we collect data on the used good's listing date, the number of used goods available for sale, seller characteristics, the offer position, the initial listing price, and the good's quality condition. The product condition was self-reported by the seller and was classified as either "New”, "Like New," "Refurbished”, "Very Good," “Good," or "Acceptable". These conditions are coded in our dataset on a scale from 1 to 6, with 6 denoting the highest quality (New) and 1 denoting the lowest grade (Acceptable). See Figure 1a for an example of a screenshot of the product condition description page on Amazon's used good market. From the new good market section on Amazon, we also collect data on the new good price listed by the manufacturer, the retailer's price for the new good, the sale rank, and the average valence and volume of reviews for that product.

Seller Reputation: The reputation data from Amazon's marketplace includes a summary of scores (or ratings) given to each seller by buyers who have completed transactions with that seller in the past. The ratings are on a scale of $1-5$ stars. All ratings $<=2$ are denoted as negative whereas all ratings $>=4$ are denoted as positive. A rating of 3 is categorized as a neutral rating. These ratings are also averaged for an overall feedback rating displayed on each seller's profile. In addition to an average overall score, Amazon also reports the number of positive, neutral, and negative postings obtained over the seller's lifetime. In our sample, the proportion of neutral ratings was extremely small (about $1.5 \%$ on average), and hence in our robustness tests, we focus 
only on the proportion of positive and negative ratings. See Figure $1 \mathrm{~b}$ for an example of a screenshot of the reputation profile of a seller on Amazon. Some typical positive and negative comments are listed in Table A1 in the Appendix.

The sellers on Amazon's used-good market are individuals and larger, well-established sellers called “Pro-Merchants”. Examples of Pro-Merchants are Office Depot and J\&R, who despite being Amazon's competitors, are allowed to sell products on its marketplace. Amazon makes money through listing fees (\$ 0.99 per listing) as well as used-good commission fees (a percentage of the used-good selling price that ranges between 6 and 15\%). Amazon waives the listing fee for "Pro Merchant Subscribers, instead charging them a fixed fee per month for membership. Specifically, there were 62 unique sellers of PDAs, 83 unique sellers of digital cameras, 87 unique sellers of audio players, and 102 unique sellers of laptops. Only a fraction of all sellers who posted a used good listing made a sale during the 5-month period of our data.

Used Good Sales: Amazon added a new variable to their XML data feed in 2004 which allows us to obtain accurate measures of used good sales. Basically, Amazon added a unique product identifier, known as a Listing ID for each product listed in the used-good market. Similarly, each seller is also given a unique Seller ID by Amazon. To test our first hypothesis, we need to find the time period that the used goods circulated in the market. Hence, we need to gather information on the sale time of used products from our data. We need information on which good sold on which date (say, day Y) after being listed on day X. Towards, this we formulate a dataset of used-product sales, using Amazon.com's XML data feed for website use techniques similar to prior work in that area (Ghose et al. 2006). Our marketplace sales data were collected once every 8 hours and included all used good offers on a given date for each product. The presence of XML-based data let us infer the price at which the good was sold, the sale date, all relevant details for competing offers of identical products, the number of used goods listed, and the total volume of sales for a given product by a given seller on a given day. As we could observe all the unique listing IDs and the unique seller IDs for the duration that a product was listed before a sale, we could also infer relevant data of all its competitors for any given seller at the time a transaction occurred and impute the number of competitors as well as their offer prices, reputation ratings, and product conditions at the time of each transaction.

Brand Reliability: To check the impact of intrinsic reliability of these brands on usedgood trade patterns, ratings from Consumer Reports, and other auxiliary sources, such as CNET, we classify the products a priori by constructing reliability rankings. For instance, within the category of digital cameras, Sony and Panasonic have higher reliability ratings while Vivitar and Samsung have lower ratings. According to Consumer Reports, these ratings were based on 186,900 reader responses to the 2005 Annual Questionnaire about digital cameras bought new 
between 2002 and 2005. Based on these sources, we compute an ordinal reliability ranking for the products. ${ }^{4}$ Table 6 in the Appendix provides a summary of the reliability rankings and demonstrates that distinct brands exhibit considerable variation in their intrinsic reliability.

Other Controls: A potential factor that might affect differences in turnaround times is consumer search costs. On the Internet, heterogeneity in search costs can arise from differences in willingness to scroll down the screen (Brynjolfsson et al. 2004). It is possible that consumers find it costly to scroll down the screen and observe all offers since this act involves a cognitive cost in evaluating multiple listings. Thus, it is plausible that consumers who inspect higher screens only and buy accordingly, chose to do so because they might care only about price (Brynjolfsson et al. 2004). On the other hand, consumers who inspect lower screens might to do so since they care about non-price factors, such as product quality and seller characteristics.

On the Amazon marketplace, this search cost effect is mediated by the fact that even though the used good offers are arranged in order of increasing price as one scrolls down the screen, higher quality products are displayed on the higher screens and the lower quality categories are displayed on the lower screens. Hence, from a consumer's point of view, there appears to be two countervailing effects from quality and price that could alleviate the net impact on sale time from the search cost-related factors. Nevertheless, for the sake of robustness, we do account for the position of any given used offer on the screen by controlling for it in our empirical estimations. Amazon displays up to a maximum of 25 offers on a screen, followed by 25 more offers on the next screen and so on. The summary statistics of the variables for each product category are presented in Tables 2, 3, 4, and 5. Note that secondary datasets are typically more objective and have several advantages compared to primary data, including but not limited to, the absence of response bias that may be present in primary data.

\section{EMPIRICAL ANALYSIS AND RESULTS}

\subsection{Time-to-Sale, Product Uncertainty, and Seller Uncertainty}

To test Hypotheses 1, 2a, and $2 \mathrm{~b}$ that examine the impact of product quality and seller reputation on sale time, respectively, our dependent variable is the natural log of Sale Time. We estimate the following panel data model:

$$
\begin{gathered}
\operatorname{Ln}(\text { Sale Time })_{i j t}=\lambda_{0}+\lambda_{1} \operatorname{Ln}(\text { Sale Price })_{i j t}+\lambda_{2} \operatorname{Ln}(\text { Seller Rating })_{i j t}+\lambda_{3} \operatorname{Ln}(\text { Life })_{i j t}+ \\
\lambda_{4} \operatorname{Ln}(\text { Condition })_{i j t}+\lambda_{5}(X)_{i j t}+\mu_{i j}+\xi_{i j t}
\end{gathered}
$$

\footnotetext{
${ }^{4}$ To be precise, we construct an "unreliability ranking” of these products, by simply reversing the order of reliability ranking. This coding is done to facilitate easier interpretation of the coefficients in the equation (2).
} 
where $i, j$, and $t$ index product, seller, and date, respectively. ${ }^{5}$ To control for unobserved heterogeneity across sellers and products, OLS regressions are estimated with product-seller fixed effects. The independent variables are the seller's reputation rating, the number of ratings (or feedback postings) of the seller, the condition of the used product, and a vector of other control variables $(X)$. The control variables include the sale price, number of competitors, and the position of a used good offer on the screen relative to competing offers. $\xi_{i j t}$ is a product-seller-time idiosyncratic error term and $\mu_{i j}$ is a product-seller fixed effect. ${ }^{6}$ Our initial estimates focus on numeric feedback scores and ignore all text-based feedback completely. Subsequently, in Section 4.1.1 we discuss the results with the content analysis of textual feedback.

A potential concern in this estimation is that Sale Price can be endogenous. We address this using Two Stage Least Squares (2SLS) with Instrument Variables. We first discuss the OLS results, and subsequently, in Section 4.1.2, we discuss the 2SLS results.

Our primary interest for testing H1 lies in the parameter $\lambda_{4}$ which captures the relationship between product condition and sale time. The estimates are presented in Tables 7, 8, 9, and 10. From Column (2) in these tables, we see that $(\beta=0.001$ and $p>0.01$ for PDAs, $\beta=0.035$ and $p<0.001$ for digital cameras, $\beta=0.1$ and $p<0.001$ for audio players, and $\beta=0.03$ and $p<0.001$ for laptops). To summarize across all Columns, the coefficient of Product Condition while positive for all four categories, is statistically significant for audio players and laptops in all specifications (Columns 1, 2 and 4 in Tables 9 and 10, respectively), and for digital cameras for some specifications (Columns 2 and 4 in Table 8). Controlling for price and seller characteristics, such as reputation score and number of postings, our analyses implies that an increase in the quality of the used good leads to an increase in the sale time of the product in the used-good marketplace in three of the four categories. Thus, this test provides support for H1, namely, that higher quality goods do take a longer time to sell than lower quality goods in dynamic used-good markets.

It is useful to note also how these estimates can be interpreted. Given that the range of

\footnotetext{
${ }^{5}$ To account for potential non-linearities and smooth large values, we use the log of the independent variables that is consistent with the literature (Ba and Pavlou 2002, Ghose et al. 2005). To be precise, because some values of Life are equal to zero, we take the logarithm of one plus the values of these variables.

${ }^{6}$ Robust standard errors are used in all regressions to account for serial correlation and heteroskedasticity, based on the Durbin-Watson test and the Breusch-Pagan test, respectively (Woolridge 2002).

${ }^{7}$ The fixed effects estimator uses variation within observations over time. The basic specification includes observations of dependent and independent variables for each product-seller in each cross sectional time period and a time invariant vector of characteristics representing unobserved heterogeneity across products and sellers. The random effects estimator is a generalized method of moments (GMM) estimator that is just a matrix-weighted average of the between and within estimators where the weighting matrix accounts for correlation across observations in the residuals. The fixed effects model does not make the assumption of zero correlation between the regressors and the individual specific effects, while the random effects model makes this assumption. The random effects model brings efficiency gains and the ability to estimate time invariant covariates at the risk of inconsistency. To test the consistency of the random effects estimator, one needs the Hausman test (Woolridge 2002). In our data, the Hausman test reveals that fixed effects are appropriate compared to random effects.
} 
condition of a used product can vary from 1-6, a 1- point increase in the quality of the used good can be a significant percentage increase in product quality. Specifically, a jump in used-good quality from 5 to 6 is equivalent to a $20 \%$ increase in used quality, a jump from 4 to 5 is equivalent to a $25 \%$ increase in used quality, and so on. A 1-point increase in the log of used product condition leads to an increase in the log of sale time ranging from $3 \%$ for laptops and digital cameras to as much as $14 \%$ for audio players.

We next discuss the tests of H2a and H2b. Column (2) includes the proportion of positive and negative feedback for sellers (but excludes the neutral feedback). For all the 4 categories, we find that the impact of an increase in the proportion of positive feedback postings (PLife) on sale time is positive and statistically significant $(\beta=0.1$ and $p<0.001$ for PDAs, $\beta=0.21$ and $p<0.001$ for digital cameras, $\beta=0.03$ and $p<0.001$ for audio players, and $\beta=0.1$ and $p<0.001$ for laptops). Similarly, the effect of an increase in the proportion of negative postings (Nlife) is negative and statistically significant $(\beta=-0.06$ and $p<0.001$ for PDAs, $\beta=-0.1$ and $p<0.001$ for digital cameras, $\beta=-0.04$ and $p<0.001$ for audio players, and $\beta=-0.07$ and $p<0.001$ for laptops). The impact of an increase in seller numeric reputation score on sale time is also positive and statistically significant. For example, from Column (2) we can see $\beta=0.06$ and $p<0.001$ for PDAs, $\beta=0.18$ and $p<0.001$ for digital cameras, $\beta=0$. 39 and $p<0.001$ for audio players, and $\beta=$ 0.79 and $p<0.001$ for laptops. Further, the marginal effect of an increase in the size of the seller (as indicated by the number of transactions that the seller completed) on sale time is always positive. These results lend support to $\mathrm{H} 2 \mathrm{a}$ and $\mathrm{H} 2 \mathrm{~b}$.

We also estimate a model that includes the interaction of seller reputation with product quality to see if the predicted positive association between sale time and higher product quality is stronger when the seller has a lower reputation rating. This finding would give a sense of the extent of complementarity or substitution between seller-level information and product levelinformation. For the first approach, we use dummy variables for both low seller reputation and high product condition to capture the interaction effects. Specifically, to code "low reputation sellers", we create a dummy variable equal to 1 if the seller reputation rating was less than 4 . In the same fashion, to code "high quality products", we created a dummy variable equal to 1 if the product condition score is greater than or equal to 5 . We then interact the two dummy variables and estimate the model. We still find that higher quality products and higher reputation sellers take a longer time to sell, thereby validating H1, H2a, and H2b. The coefficient of the interaction term is statistically significant only for the laptop category, while the direct effect of each of the two variables is bigger than the interaction term, as seen in Column (3) in Tables 7 through 10. The directional nature of these results was robust to different specifications used to capture the 
interaction effects. ${ }^{8}$ The results suggest that there is no consistent evidence of complementarity or substitution effects for product-level and seller-level information to affect information asymmetry.

\subsubsection{Content Analysis of Reputation Profiles}

One could argue that seller reputation rating contains information related to both a seller's service quality and product condition. In such a scenario, it is plausible to increase the precision in the empirical estimations by splitting a seller's reputation rating to reflect the seller and product information embedded in that reputation separately.

To check for the robustness of analyses, we perform an additional set of analysis by using content analysis techniques to parse the buyer-generated textual feedback in the sellers' reputation profiles. User-generated transaction feedback has now proliferated in the reputation systems of major online markets, such as Amazon and eBay. It has been shown by an emerging stream of research that textual feedback posted by buyers does influence seller's pricing power and the probability of a sale over and above the numeric ratings summarized in the used product marketplace (Ghose et al. 2005, 2007). Hence, the qualitative information contained in text-based feedback is used here to unravel the two dimensions of reputation contained in the ratings.

Content analysis is a popular technique in research (e.g., Kolbe and Burnett 1991, Pavlou and Dimoka 2006) and is applied to transform the meaning of text comments into objective data, using systematic procedures to ensure both objectivity reliability of a data analysis (e.g., Weber 1990). Toward this goal, feedback text comments are classified as product-condition related if they reflect some aspect of product quality. Those comments referring to service quality of the seller are classified as seller-service related. We use two human annotators for this study. For each of the four product categories in our data, the annotators read the reputation feedback postings of all the sellers who made a transaction and identified whether the feedback postings in each seller profile contained comments about either or both dimensions. The presence or absence of each kind of comment is coded as a dummy $(0,1)$ variable. The content analysis examines a total of 25 comments per seller across the first two pages. ${ }^{9}$ This method is similar to that used by Pavlou and Dimoka (2006), who indicate that buyers typically do not view comments beyond the first two pages. See Table A1 in the Appendix for examples of such feedback.

Our sampling scheme produced a total of 7, 552 feedback comments coded for content analysis (there were some common sellers who overlapped across the product categories) by each of the two annotators. To test the reliability of the content analysis, a reliability score is calculated

\footnotetext{
${ }^{8}$ Using an alternate approach, we also ran interaction effects with a continuous measure of one variable and a dummy variable for the other. All the results were qualitatively the same as the existing ones.

${ }^{9}$ The default number of comments on a single page on Amazon is 25. While the first page of the seller's profile shows 5 comments, when the user goes to the second page, it shows a total of 25 comments that include the 5 comments shown on the first page.
} 
for each of the two categories. We calculate Perrault and Leigh's (1989) reliability index, wherein the authors independently evaluated a sample of the text comments and compare their results with those of the coders. This score was 0.92 and 0.88 for seller service-related and product conditionrelated feedback, respectively. The values also exceed Perreault and Leigh's (1989)

recommendation of 0.8 . We also measure the inter-rater agreement across the two coders, using the Kappa statistic. This analysis shows substantial agreement with a Kappa of 0.77. All the analyses suggest high reliability of our content analysis.

Thereafter we determine the implicit contribution of seller service-related and product condition-related textual feedback to a seller's overall reputation. To infer the reputation of a seller along the seller-related dimension, we divide the sum of the seller's reputation rating for each posting with seller-related information by the frequency of the 'seller-related' dummy variable across all the postings. This becomes the seller service-related rating variable. Similarly, we divide the sum of the seller's reputation rating for each posting with some product-related information by the frequency of the 'product-related' dummy variable across all the postings. This becomes the product condition-related rating variable. The procedure enables us to apportion the magnitude of the effect of these two components on seller reputation score and split the seller reputation rating into two components, one that reflects seller service and the second reflecting product condition-related information.

We provide the results from the analysis of this data sample in Column (4) of Tables 7-10. The sign on each of the two dimensions of reputation ratings is positive and statistically significant, and the estimates for the other variables remain qualitatively unchanged. These estimates verify that the main results for $\mathrm{H} 1, \mathrm{H} 2 \mathrm{a}$ and $\mathrm{H} 2 \mathrm{~b}$, remain qualitatively the same even if we were to apportion seller reputation scores into these two components by incorporating textual feedback.

\subsubsection{Instrument Variables Estimation With 2SLS}

While Equation (1) can be estimated using a panel data fixed effects model, a concern for this strategy is potential endogeneity of sale price. To control for this potential problem, we estimate a Two-Stage Least Square (2SLS) regression using instrument variables (Woolridge 2002). Commonly used instruments for prices are not available to us. For example, lack of marginal cost data rules out cost-side instruments, and lack of regional data rules out "Hausman"style instruments. Due to this limited supply of available instruments, we follow prior work and use a one-period, lagged value of listing price as the instrument (Villas-Boas and Winer 1999). Admittedly, the lagged price might not be an ideal instrument since it is possible to have common demand shocks correlated over time, and then lagged prices would be correlated with the current 
period demand shock. However, common demand shocks correlated through time are similar to trends. Hence, a suitable control for correlated demand shocks or trends in the 2SLS equation can alleviate these concerns.

Towards this, we use data on the online search volume of these products. Specifically, we use data on the "product search volume" of the different products in our sample from Google Trends to control for exogenous demand shocks that may be correlated over time. For each product, we retrieve a search volume graph from the Google Trends website. This graph represents the number of search queries for a particular product name submitted to Google. We then digitize the trend data, using Engauge Digitizer software and use the log of the search volume as a proxy variable in the regression, similar to the methods in Archak et al. (2008). These results are qualitatively the same and presented in Column (5) of Tables 7-10. ${ }^{10}$

These results imply that although there seems to be some time-based, efficient sorting going on in used-good markets between sellers of high and low quality products and sellers of high and low reputation ratings, the presence of some seller-based and product-based information uncertainty creates impediments in the efficient allocation of used goods. Thus, our analysis suggests that information asymmetries associated with adverse selection continue to exist in some electronic used-good markets.

\subsubsection{Other Robustness Checks}

It is possible that inexperienced sellers' used-good offers (where experience is measured based on the number of recorded feedback postings) differ from those of experienced sellers in some unobservable manner, and these different choices lead to different trade patterns in equilibrium. For example, larger sellers who have multiple units of the same product available for sale may derive a lower use value from holding on to the used good. While these differences can be captured in the product-seller fixed effects, we examine the data in greater detail by stratifying it in different ways. Specifically, we create a dummy variable that took the value of 0 or 1 , depending on whether the seller had between 1 and 100,000 postings or more than 100,000 postings, respectively. This classification produces two categories of sellers based on the number of prior recorded transactions: Small sellers (fewer than 100,000 transactions) and large sellers (more than 100,000 transactions). We find that an increase in product condition as well as an increase in seller rating and seller feedback postings still positively relates to sale time and is statistically significant for all four categories, providing support for H1, H2a, and H2b. These results are also very robust to the use of three classes of sellers based again on the number of

\footnotetext{
${ }^{10}$ Results are robust to the use of more than one period lag of the used good listing price. Further, regressions of sale prices on polynomials in lagged list prices reject serial correlation in residuals that use the Box-Pierce-Lung statistic (Ljung and Box, 1978).
} 
recorded transactions: Small sellers (fewer than 50,000 transactions), medium sellers (between 50,000 and 100,000 transactions), and large sellers (more than 100,000 transactions). Finally, it is possible that sellers may not derive a residual value from using the highest quality good ("new good”) in order not to degrade their qualities and thereby lower the exchange value. Hence, we also carried out the entire analysis after excluding the "new" goods in our data. Again, we find strong support for H1, H2a and H2b. These results are shown in the Appendix in Tables A1-A4.

In addition to the above tests, we also experimented with a broad array of other control variables, such as (i) Amazon sales rank of the new good to control for the average popularity of the product at the time a sale occurred in the used-good market; (ii) the valence and volume of reviews received by the product in the new good market at Amazon to control for potential wordof-mouth effects driving sales; (iii) the manufacturer's list price for the product; (iv) Amazon's retail price; (v) the number of days since the product was available on the market (which can proxy for the average age of the product); (vi) dummy variables for the month to control for seasonal variations; and (vii) data on competitor reputation scores and offered product conditions. None of these specifications led to any qualitative change in our results, and hence the details are omitted for brevity.

Finally, note that "within R-squared" values of our models ranged between 0.02 and 0.19 across the four product categories because these R-squared values are for the "within" (differenced) fixed-effect estimator that estimates this regression by differencing out average values across product sellers. This means that the calculated “within” R-squared values not take into account the explanatory power of the fixed effects. If we estimated the fixed effects instead of differencing them out, the measured R-squared would be much higher (between 0.66 and 0.88 ) as can be seen from the row titled "R-squared with fixed effects" in Tables 7-10.

\subsection{Price Decline, Trade Volumes, and Reliability}

Hypotheses 3a and 3b for the relationship between price declines, product reliability, and trade volume is a relatively direct test of the presence of adverse selection. As discussed, this test is based on an empirical framework similar to that used by Gilligan (2004). The dependent variable constructed was the natural log of Price Decline where Price Decline is the ratio of the difference between Manufacturer Price (price of the new good) and Sale Price (price of the used good) over the Manufacturer Price. ${ }^{11}$ That is, the price decline measures the extent of the residual value of the used product at any given point in time. The higher the residual value, the lower will be the price decline. Within each of the four categories, we aggregate products into "models"

\footnotetext{
${ }^{11}$ The qualitative nature of our results is robust to the use of Amazon's retail price for the new good instead of the manufacturer's list price for the new good.
} 
based on the make and type of the product. ${ }^{12}$ Since there are few instances of a seller-model combinations sold on a daily level for some products, we aggregate the transactions at a weekly level and use 'week' as the unit of time to maintain consistency in the analyses across the four categories. Similar to Gilligan (2004), we estimate models of the form:

$$
\begin{gathered}
\text { Ln(PriceDecline })_{i j t}=\lambda_{0}+\lambda_{1} \text { Unreliability }_{i j t}+\lambda_{2} \operatorname{Ln}(\text { Trade Volume })_{i j t}+ \\
\lambda_{3}(\text { Unreliabilty } * \operatorname{Ln}(\text { Trade Volume }))_{i j t}+\lambda_{4}(X)_{i j t}+\mu_{i j}+\xi_{i j t}
\end{gathered}
$$

where $i, j$, and $t$ index the model, seller, and time, respectively. $X$ denotes the control variables such as Rating, Life, Condition, and Competitors. $\xi_{i j t}$ is an idiosyncratic error term and $\mu_{i j}$ is a model-seller fixed effect. The Unreliability variable reflects the extent to which the brand is intrinsically not reliable. Thus, higher values of the Unreliability variable indicate lower brand reliability. The Trade Volume variable captures the total volume of used goods of a specific model sold by a seller in a given week.

A potential concern in this estimation is that price declines and trading volumes may be jointly determined by other factors. Because of possible endogeneity concerns, OLS may produce biased estimates of the relationship between trade volume and price decline. We address this using Two Stage Least Squares (2SLS) with Instrument Variables. We first discuss the OLS results, and then subsequently in Section 4.2.1, we discuss the 2SLS results.

Our primary interest is in the parameter $\lambda_{2}$, which captures the relationship between trade volume and price decline, and in $\lambda_{3}$ which captures the interaction effect of unreliability for this relationship. However, because both Trade Volume and Unreliability are continuous variables, the interaction effect needs to be carefully measured and interpreted. ${ }^{13}$

The estimates for each category are reported in Tables 11-14. A number of interesting results emerge from this analysis. First, note from Columns (1) and (2) that the sign on the coefficient for Unreliability, $\lambda_{1}$, is positive and statistically significant for digital cameras $(\beta=$ 0.33 and $p<0.001)$, PDAs $(\beta=0.05$ and $p<0.001)$ and laptops $(\beta=0.042$ and $p<0.001)$. This finding implies that there is an indeed a positive relationship between price decline and increased

\footnotetext{
${ }^{12}$ For example, an Apple iPod can have three models associated with it - the 'Shuffle', 'Nano', and the 'Classic'. Under this classification, a green, black or purple 'Shuffle' all belong to the model 'iPod Shuffle'. Note that we cannot identify parameters of interest when we include product fixed effects since the unreliability rankings are from the year 2005 and hence, are correlated with the unique product identifiers in the dataset with no variation over time. In an alternate specification, we ran regressions that included product-seller random effects. We found no change in the qualitative nature of the main results.

${ }^{13}$ We are interested in the regression of Price Decline on Trade Volume at particular values of Unreliability. The $\left(\lambda_{0}+\lambda_{1}\right.$ (Unreliability) term is the simple intercept, and the $\lambda_{2}+\lambda_{3}$ (Unreliability) term is the simple slope. To examine the interaction, we must choose particular values of Unreliability at which to compute the slopes. Since it is common for researchers to choose the mean, one standard deviation below the mean, and the maximum, we conduct our analysis accordingly. Further the variables are also mean-centered to enable easier interpretations of the interactions and minimize potential problems with multi-collinearity (Aiken and West 1991).
} 
unreliability of the product as hypothesized in H3a. The coefficient on the interaction of unreliability and trade volume, $\lambda_{3}$, can be interpreted as the amount of change in the slope of the regression of Price Decline on Trade Volume when Unreliability changes by one unit. We use the relevant numbers from the descriptive statistics, and plug them into the expressions that determine the marginal impact of Unreliability on the relationship between Trade Volume and Price Decline.

All else being equal, we find that for two of the four categories, products with higher levels of unreliability, exhibit a more negative relationship between trading volume and price decline, thereby supporting H3b. Specifically, do note from Column (2) that the sign on the coefficient for the interaction term, $\lambda_{3}$, is positive and statistically significant for digital cameras ( $\beta=-0.041$ and $p<0.001)$ and laptops $(\beta=-0.005$ and $p<0.001)$. For PDAs, while there are some regions over which price declines grow steeper and volume of trade become lower as the inherent unreliability of the product increases, the evidence here is relatively weaker than for the other three categories.

In summary, our analysis reveals that Hypotheses 3a and 3b hold true for several products, implying that these products are subject to the adverse selection problem in the online used-good market. ${ }^{14}$ These findings are consistent with the notion that when asymmetric information exists in used-good markets, efficient sorting and allocation fails to occur in that market. As postulated by Hendel and Lizzeri (1999), the lower volume of trade for used goods can be attributed to adverse selection. Note again that as before in Section 4.1, the low “within R-squared” values occur because we difference out the fixed effects in our estimations. If we estimated the actual dummy variables, the same model would yield significantly higher R-squared values.

In summary, this test provides further empirical evidence of the existence of adverse selection among a variety of used electronic products in dynamic and decentralized electronic used-good markets, such as Amazon, where there is a continuous entry and exit by buyers and sellers. While we are able to shed light on how these products exhibit differences in trading patterns, inferring the exact cause of those differences is not possible from our data. It is possible that used audio players display more homogeneity- and commodity- like features than do used PDAs, digital cameras, and laptops. This aspect could mitigate information uncertainties in the minds of consumers. It is also possible that these particular products are relatively less expensive than those in the other three categories, and this variation might play a role in determining the extent of purchase involvement in a market with information asymmetry (Pavlou et al. 2006).

\footnotetext{
${ }^{14}$ We conducted the VIF (Variance Inflation Factor) test for all regression models and found no evidence of multicollinearity among the independent variables. The VIF scores for all variables are lower than the commonly accepted level of 10 (Kennedy 2003).
} 


\subsubsection{Instrument Variables Estimation With 2SLS}

In models of trade for used durable goods, price declines and trading volumes may be jointly determined by such factors as distribution of buyers tastes, rates of durable good quality depreciation, and realizations of used-good quality (Gilligan 2004). Because of possible endogeneity concerns, OLS may produce biased estimates of the relationship between trade volume and price decline. To better evaluate that relationship, we estimate a Two-Stage Least Square (2SLS) regression using instrument variables. As before, we are stymied by the limited supply of available instruments. We exploit the panel dimension of the data and use lagged values of explanatory variables as an instrument, consistent with prior work (Villas-Boas and Winer 1999). If there is sufficient variation over time in the lagged independent variable, then there is less likely to be correlations amongst common errors and hence they are more likely to be suitable instruments (Villas-Boas and Winer 1999). This choice does not lead to any qualitative change in the results as can be seen from Columns (3) and (4) in Tables 11-14. It should be noted however that if the lagged independent variable is correlated with current period shocks, then the 2SLS model will underestimate the true effect of trade volume. As a robustness check, we also experiment with a broad array of other control variables, such as the average review rating for the new good, competitors' reputation ratings, and the condition of their products. These controls did not affect the qualitative nature of the results, thus finding support for H3a and H3b.

\subsubsection{GMM Estimation}

It is possible that the price decline in the current period is affected by the extent of price decline in the previous period. For example, sellers' choices regarding the listing price that affect the volume of trade in previous periods could potentially affect the sale price in the current period. Hence, we estimate a dynamic panel data estimator, such as the Arellano-Bond estimator with lagged dependent variables (lagged value of Price Decline) on the right hand side of equation (2). ${ }^{15}$ A potential difficulty with the DGMM estimator is that lagged levels may not be good instruments for first differences when the underlying variables are highly persistent over time. Arellano \& Bover (1995) and Blundell \& Bond (1998) propose an augmented estimator commonly referred to as "system GMM" (SGMM), in which the original equations in levels are added to the system. The idea is to instrument differences with lagged levels and instrument levels

\footnotetext{
${ }^{15}$ Arellano and Bond (1991) developed a Generalized Method of Moments estimator that treats the model as a system of equations, one for each time period. The equations differ only in their instrument/moment condition sets. The key idea is that if the error terms are serially uncorrelated, then the lagged values of the dependent variable and the endogeneous variable represent valid instruments. The resulting estimator is known as the "difference GMM" (DGMM).
} 
with lagged differences. We use this approach and apply the finite-sample correction proposed by Windmeijer (2005) which corrects for the two-step covariance matrix and increases the efficiency of both GMM estimators. We include time dummies to ensure that the assumption about no correlation across individuals in the idiosyncratic disturbances required for the autocorrelation test and robust estimates of the standard errors holds (Roodman 2006). The Hansen J-test suggests that the instruments as a group are exogenous. As seen from Column (5) of Tables 11-14, the estimates suggest that our results are robust, thus finding support for H3a and H3b.

\section{DISCUSSION}

\subsection{Key Findings and Contributions}

The paper offers several findings validated in two distinct, empirical analyses with panel data on four different product categories (PDAs, digital cameras, laptops, and audio players). First, this study analyzes the impact of information asymmetry on trade patterns when market failure is reflected in the length of waiting time before a seller is able to execute a trade in the secondary market, after controlling for price and other factors. The adverse selection problem exists as it takes time to separate high and low quality products, and higher quality products do take a longer time to sell than lower quality goods. The gains from eventual trading are offset by this waiting cost, and it is well-known that time preferences can play a critical role in determining the net social surplus (Janssen and Roy 2004). We find that despite the presence of quality indicators, such as seller-disclosed product condition and buyer-generated reputation feedback, the adverse selection problem is not completely alleviated in online used-good markets. Thus, this paper corroborates predictions based on recent theory on dynamic and decentralized markets where goods of varying quality are available for sale by sellers of varying reputation. This research is the first empirical study that considers time as a dimension for efficient sorting in online markets, thereby extending the prior work that looked at determinants for the duration of ownership to examine the presence of asymmetric information in offline markets (Sirmans et al. 1995, Nagler and Osgood 2006).

Second, the paper examines the inter-relationship between product reliability, trade volumes, and price depreciation. It provides direct evidence of the existence of the lemon problem based on this relationship as theorized by Hendel and Lizzeri (1999), and then shown by Gilligan (2004). By empirically demonstrating an inverse relationship between steeper price declines and lower volumes of trade and showing that this relationship is stronger for less reliable brands, this paper offers evidence of the presence of quality-based information asymmetry for digital cameras, PDAs, laptops and audio players in electronic markets. This is the first paper that uses this test of 
adverse selection in an online context, thereby extending the work of Gilligan (2004) who has demonstrated adverse selection in offline markets for used business aircraft using the same framework.

How do these findings extend the prior work and contribute to the literature? Prior theoretical research on adverse selection shows that when there is information asymmetry in static markets, higher quality goods are less likely to be traded despite the potential gains from that trade. However, empirical evidence of this theory has been found to be mixed in both offline markets and more recently in online markets even within the same category -- that of used cars (Fabel and Lehmann 2000, Garicano and Kaplan 2001, Emons and Sheldon 2002, Adams et al. 2005, Wolf and Muhanna 2006, Overby 2008). Much of the prior empirical analyses are based on testable predictions from models that considered static markets. Online markets exhibit more dynamic characteristics due to the entry and exit of buyers and sellers.

Recently, a few theoretical papers have shown that in dynamic used-good markets with entry of traders, the inefficiencies caused by information uncertainty can manifest themselves as temporal effects in various trading patterns (Janssen and Karamychev 2002, Blouin 2003, Janssen and Roy 2004) and price dynamics (Hendel and Lizzeri 1999, Gilligan 2004). However, no work to date has tested for clear empirical evidence of information asymmetry in electronic markets based on predictions from these dynamic models. This motivates the need to test and quantify the effects of information asymmetry in markets by drawing on predictions where time can be used as a sorting mechanism in addition to price. Our paper bridges this limitation to address a managerially relevant problem.

Further, other than Dimoka and Pavlou (2008), prior work has subsumed product uncertainty within seller uncertainty without explicitly defining them as two separate constructs. However, because of changes in both product and seller characteristics over a given period of time, information uncertainty can arise from both sources. This is particularly true in electronic markets where buyers and sellers are separated by time and space, and product quality signals may not be easily conveyed by sellers. This paper distinguishes between product- and sellerinduced information uncertainty, and separately measures the impact of each. We thus extend the literature on seller reputation theories (for example, Klein and Leffler 1981) by analyzing the role of product information in affecting information asymmetry. We do not find any consistent evidence of substitution or complementarity effects between product-level information and sellerlevel information in alleviating information uncertainty. In this regard, our paper particularly differs from the extant work that finds either substitution (Anand and Shachar 2004) or complementarity (Dimoka and Pavlou 2008) effects between the two constructs.

A third feature of much of the prior work on adverse selection in electronic markets is that 
it all has been done in the context of auctions where final sale prices are primarily determined by buyers’ valuations and bidding behavior (Dewan and Hsu 2004, Adams et al. 2005, Wolf and Muhanna 2006) rather than in posted price markets, such as online used-good markets where the starting and ending prices are primarily determined by sellers. Hence, our understanding of how information uncertainty affects dynamics in posted price markets is still nascent. A deeper understanding of the price decline process can create appropriate incentives for sellers to price the used good accordingly, especially when simultaneously selling new goods. In this vein, our paper contributes to the literature examining interactions between new and used good markets and its impact on seller profitability (Aron and Sundararajan 1998, Ghose et al. 2005, 2006, 2007).

\subsection{Implications for Practice}

Our paper demonstrates that despite the presence of reputation systems that contain usergenerated feedback on sellers' transaction history, online used-good markets remain susceptible to certain adverse selection problems. While seller ratings have been used to measure reputation effects in prior work (Dellarocas 2003), the role of these systems in influencing market mechanism design is only just emerging, as noted by Bapna et al. (2004) in the context of online auctions and Ghose et al. $(2005,2007)$ in the context of posted price markets. It is well known that asymmetric information can produce negative effects on the level of welfare generated by a market. Our paper provides a descriptive analysis of the temporal nature of the various effects, a finding that can be used to make prescriptive managerial recommendations on market design to enhance social welfare and consumer surplus (Ghose et al. 2006, Bapna et al. 2008).

The existence of adverse selection has interesting implications for merchants who are contemplating trading on electronic markets and also for intermediaries who host these markets. An ongoing concern is whether sellers may misrepresent the true quality of the used good. Since information uncertainty affects higher quality sellers more than others, market makers can invest in tools that do a better job in communicating reliable product information to buyers. Product diagnosticity allows buyers to accurately evaluate a product's quality (Jiang and Benbasat 2007). Since accurate disclosure of product condition tends to affect both sale time and trade volume, market makers could benefit from newer mechanisms that enable sellers to reveal information about the true quality of the used products. This could include information on the number of repairs, the use of extended warranties, or the vintage record of the product, i.e., the number of distinct consumers who have used it in the past and the duration of their ownership. Hendel and Lizzeri (2005) have shown that it is possible to employ the vintage of the used good to signal its quality and lead to efficient sorting in used good markets. Reputation systems could also place higher weightage on more recent transactions since it has been shown that under such a 
mechanism, the optimal strategy of a high quality seller is to always advertise honestly (Aperjis and Johari 2008). This is consistent with eBay's recent decision to base the Positive Feedback percentage on the past 12 months of feedback, rather than the entire lifetime of the seller.

Our analysis of user-generated reputation feedback suggests that buyers do consider the textual content posted in the reputation profiles of sellers before making a purchase decision. To the extent that information extracted from user-generated textual feedback and displayed in a user-friendly manner can facilitate increased trust between buyers and sellers, our study demonstrates the need for designing more robust reputation systems that explicitly display several dimensions of a seller's reputation such as customer service, packaging, shipping, product representation, etc. Websites can use drop-down menus to highlight sellers' scores for these dimensions (Ghose et al. 2005, Ghose et al. 2007, Pavlou and Dimoka 2006), customized by product category. Such seller and product diagnostic features on websites can go a long way toward mitigating the information asymmetry problem in online used-good markets.

The analysis of sale time and its relationship to various product and seller characteristics enables a prediction of future demand from sale price information. Basically, sellers can learn demand patterns from the final price of current transactions and then bolster future profits by procuring the good only in periods of high demand. This information will allow merchants to optimize product assortment decisions and minimize costs of inventory for slow-moving products. This seems important in an online used-good market where sellers can differ widely based on inventory size and homogeneity.

\subsection{Limitations and Future Research}

Our paper has several limitations that, nevertheless, create opportunities for future research. For example, it is possible that some vendors cross-list the same product across multiple websites. We cannot infer whether vendors in our dataset engaged in such practices. However, this circumstance would not bias our results as long as sellers did not systematically remove listings in the absence of a sale. There is no particular reason to believe that sellers on Amazon engage in such practices and so this is not a big concern in our paper. However, if this activity were to have occurred in our data, it would have led to an overestimation of the actual number of sales. Accounting for this information is then likely to increase the average sale times. Thus, this would further reinforce the presence of adverse selection in the market. Future work can use transaction data from a pool of common sellers across these markets (for example, sellers who sell on both Amazon and eBay) to verify the robustness of our results.

Future work can also examine whether the extent of adverse selection varies in different markets by comparing lower purchase involvement products (e.g. books, CDs) to higher purchase involvement products. The scope of information uncertainty was restricted in this study to seller 
and product quality aspects, excluding uncertainty sources due to third parties, such as online certification intermediaries that are common in certain categories like the used car market. Future work can attempt to broaden the scope of uncertainties and examine their effects. While our content analysis did demonstrate robustness of the qualitative nature of our results, future research can further use automated text-mining methods (Ghose et al. 2005, Ghose et al. 2007, Archak et al. 2008, Ghose and Ipeirotis 2008) to more precisely examine the value of textual feedback in mitigating adverse selection.

We did not have information on the actual product descriptions of the used goods provided by sellers in the marketplace. Sellers in online markets use a variety of textual phrases such as "brand new, "pristine condition", "not highlighted", etc, to describe the condition of the used good. Thus, the information on product quality captured in this study may be some function of the true quality (strategically chosen, for example, in a disclosure model). While our productseller fixed effects do alleviate this concern, especially if it were systematic, future research could examine this in greater detail. In fact, future work could incorporate seller-generated textual product descriptions to examine their effect over and beyond the numeric scores on product description used in this study. Since text reduces uncertainty, there could be strategic causal effects of information provision by sellers (Lewis 2007).

A number of other research developments are possible as extensions of this research. Since sellers of higher quality products need to wait longer than their competitors who sell lower quality products, they incur a cost of waiting to trade. Indeed, this cost of waiting is an important factor that must be considered in any estimation of welfare loss caused by adverse selection (Janssen and Roy 2004). Because of the potential inefficiencies from asymmetric information, an interesting extension of this study would involve investigating the cost of waiting for different sellers and the associated welfare changes not considered in prior work on quantifying welfare generated in Internet exchanges for used goods (Ghose et al. 2006, Bapna et al. 2008). In the long term, the introduction of other factors, such as product diagnostic tools by online markets, can alleviate the information asymmetry problem and lead to entry by more highly reputed sellers. An examination of the long- term impact of adverse selection in online markets will require a much longer time-series dataset, preferably spanning a few years.

The kind of data available from online used-good markets allows close study of the concepts of price-evolution and associated with that topic, various concepts of pricing dynamics that are similar to an emerging stream of work in online auctions (Bapna et al. 2005). An understanding of these dynamics can be helpful in characterizing demand and predicting the probability of a sale in a market made up of heterogeneous sellers selling diverse products. An analysis of pricing cycles in used-good markets can have important implications for market 
mechanism and incentive design.

From the perspective of future research in e-commerce, our findings suggest opportunities for design science research to extract information from the growing volume of user-generated content in online markets. These kinds of content can allow market makers to come up with a more judicious design of decision-making tools for such systems. Examples could be tools that enable multi-media, visual, and textual descriptions of products by sellers (Lewis 2007, Dimoka and Pavlou 2008). Further, by showing that current mechanisms for product condition disclosures have yet to alleviate the information asymmetry problem, this paper further highlights the role of

product-level uncertainty as an emerging IS research area (Dimoka and Pavlou 2008). This would extend the long stream of research that analyzes the role of seller information signals in reducing seller level uncertainty in online markets. From a research perspective, the evaluation of such recommended design features, such as drop-down menus that explicitly highlight different dimensions of sellers' reputation and mechanisms and incentives for truthful revelations of actual product quality, can be accomplished through well-designed laboratory experiments and eyetracking studies.

\section{CONCLUSION}

This paper theorizes and empirically estimates models that assess information uncertainties in Internet exchanges for used goods. Using a unique dataset collected from four different categories in the used-good marketplace on Amazon, we investigate trade patterns in a competitive electronic market and conduct two tests to demonstrate the presence of adverse selection. Akerlof (1970) suggests that mechanisms, such a branding or reputation, may mitigate the lemons problem in used-good markets. This paper documents and sheds light on the role of seller service and product quality-induced information uncertainty in creating adverse selection despite the existence of reputation systems and product condition disclosures in online, used-good markets. Our findings suggest a need for improving the design of Internet exchanges for used goods to incorporate product diagnostic features that may further mitigate the extent of information asymmetry between buyers and sellers in these particular markets. 


\section{References}

Aiken, L. S., and West, S. G. Multiple Regression: Testing and Interpreting Interactions. Thousand Oaks: Sage, 1991.

Archak, N., Ghose, A. and Ipeirotis, P. "Deriving the Pricing Power of Product Features by Mining Consumer Reviews,” Working Paper, SSRN, 2008.

Aperjis, C., and R. Johari. “Designing Reputation Mechanisms for Efficient Trade,” Working paper, Stanford University.

Arellano, M., and Bond, S. "Some Tests of Specification for Panel Data: Monte Carlo Evidence and an Application to Employment Equations,” Review of Economic Studies, (58: 2), pp. 277-297, 1991.

Arellano, M., and Bover, O. "Another Look at Instrumental Variable Estimation of Error Component Models,” Journal of Econometrics 68, 1995, pp. 29-52.

Aron, R., and Sundararajan, A. "An Economic Analysis of Electronic Secondary Markets: Installed Base, Technology, Durability and Firm Profitability,” Decision Support Systems, 24(1), 1998, pp. 3-16.

Adams, C., Hosken, L. and Newberry, P. "Vettes and Lemons on EBay,” Working Paper, Federal Trade Commission, Washington D.C., 2002.

Akerlof, G. A. “The Market for 'Lemons': Quality Uncertainty and the Market Mechanism,” Quarterly Journal of Economics (84:3), 1970, pp. 488-500.

Ba, S., and Pavlou, P. "Evidence of the Effect of Trust Building Technology in Electronic Markets: Price Premium and Buyer Behavior,” MIS Quarterly (26:3), September 2002, pp. 243-268.

Bapna, R., Goes, P., Gupta, A., and Jin, Y. "User Heterogeneity and Its Impact on Electronic Auction Market Design: An Empirical Exploration,” MIS Quarterly (28:1), March 2004, pp. 21- 43.

Bapna, R., Jank, W. and Shmueli, G. “Consumer Surplus in Online Auctions,” forthcoming, Information Systems Research, 2008.

Blundell, R., and Bond, S. "Initial Conditions and Moment Restrictions in Dynamic Panel Data Models,"Journal of Econometrics 87, 1998, pp 115-143.

Blouin, M. "Equilibrium in a Decentralized Market with Adverse Selection,” Economic Theory, 22, 2003, pp. 245-262.

Bolton, E. Katok and Ockenfels, A. "How Effective Are Electronic Reputation Mechanisms? An Experimental Investigation,” Management Science 2004, 50(11), 1587-1602.

Bond, E. W. “A Direct Test of the "Lemons” Model: The Market for Used Pickup Trucks,” American Economic Review 72(4), 1982, pp. 801-04.

Brown, J. and Morgan, J. “Reputation in Online Markets: The Market for Trust," California Management Review, 2006, (49:1), pp. 61-81.

Brynjolfsson, E., Dick, A. and Smith, M. "Search and Product Differentiation at an Internet Shopbot," Working Paper, MIT, 2004.

Dellarocas, C. The Digitization of Word-of-Mouth: Promise and Challenges of Online Reputation Mechanisms. Management Science (49:10), 2003, pp. 1407-1424.

Dewan, S. and Hsu, V. "Adverse Selection in Electronic Markets: Evidence from Online Stamp Auctions," Journal of Industrial Economics (17:4), 2004, pp. 497-516.

Dimoka, A. and Pavlou, P. "Understanding and Mitigating Product Uncertainty in Online Auction Marketplaces,” Working paper, 2008. 
Emons, W. and George, S. “The Market for Used Cars: A New Test of the Lemons Model,” Working Paper, University of Bern, 2002.

Fabel, O. and Lehmann, E. "Adverse Selection and the Economic Limits of Market Substitution: An Application to E-Commerce and Traditional Trade in Used Cars,” Working Paper, 2000.

Garicano, L. and Kaplan, S. N. "The Effects of Business-to-Business E-Commerce on Transaction Costs," Journal of Industrial Economics (49:4), 2001, pp. 463-486.

Gefen, D., Karahanna, E., and Straub, D. "Trust and TAM in Online Shopping: An Integrated Model," MIS Quarterly (27:1), 2003, pp. 51-90.

Genesove, D. “Adverse Selection in the Wholesale Used Car Market,” Journal of Political Economy (101:4), 1993, pp. 644-65.

Gilligan, T. "Lemons and Leases in the Used Business Aircraft Market,” Journal of Political Economy (112: 5), 2004, pp. 1157-1180.

Gilkeson, J. and Reynolds, K. "Determinants of Internet Auction Success and Closing Price: An Exploratory Study,” Psychology and Marketing, 20(6), 2003, pp. 537 - 566.

Ghose, A., Ipeirotis, P., and Sundararajan, A. “The Dimensions of Reputation in Electronic Markets,” Working Paper, SSRN, 2005.

Ghose, A., P. Ipeirotis and A. Sundararajan. "Opinion Mining Using Econometrics: A Case Study on Reputation Systems,” Proceedings of the Association for Computational Linguistics (ACL 2007), 2007.

Ghose, A., Telang, R., and Krishnan, R. "Effect of Electronic Secondary Markets on the Supply Chain," Journal of Management Information Systems 22, 2005, 91-120.

Ghose, A., Smith, M., and Telang, R. "Internet Exchanges for Used Books: An Empirical Analysis of Product Cannibalization and Welfare Implications," Information Systems Research, (17:1), 2006, pp. 3-19.

Ghose, A., P. Ipeirotis. "Estimating the Socio-Economic Impact of Product Reviews: Mining Text and Reviewer Characteristics,” Working Paper, SSRN, 2008.

Hendel, I., and Lizzeri, A. “Adverse Selection in Durable Goods Markets,” American Economic Review (89:12), 1999, pp. 1097-1115.

Hendel, I., Lizzeri, A., and Marciano, S. "Efficient Sorting in a Dynamic Adverse-Selection Model,” The Review of Economic Studies, 72(2), 2005, pp. 467-497.

Hsiao, C. 2003. Analysis of Panel Data. Cambridge, UK: Cambridge University Press.

Inderst, R. and Muller, H. “Competitive Search Markets for Durable Goods,” Economic Theory 19(3), 2002, pp. 599-622.

Janssen, M., and Karamychev, V. "Cycles and Multiple Equilibria in the Market for Durable Lemons," Economic Theory 20, 2002, pp. 579-601.

Janssen, M. and Roy, S. “On Durable Goods Markets with Entry and Adverse Selection,” Canadian Journal of Economics (37:3), 2004, pp. 552-589.

Jiang, Z. and Benbasat, I. "The Effects of Presentation Formats and Task Complexity on Online Consumers’ Product Understanding,” MIS Quarterly (31: 3), 2008, pp. 475-500..

Kennedy, P. 2003. A Guide to Econometrics, 5th Edition, MIT Press, Cambridge, MA.

Klein, B. and Leffler, K. “The Role of Market Forces in Assuring Contractual Performance,” Journal of Political Economy (89:4), 1981, pp. 615-641.

Kim, D. and Benbasat, I. "Trust-Related Arguments in Internet Stores: A Framework for Evaluation,” Journal of Electronic Commerce Research (4:2), 2003, pp. 49-64. 
Kirmani, A., and Rao, A. R. "No Pain, No Gain: A Critical Review of the Literature on Signaling Unobservable Product Quality,” Journal of Marketing (64:2), 2000, pp. 66-79.

Kolbe, R. H., and Burnett, M. "Content Analysis Research: An Examination of Applications With Directives for Improving Research Reliability and Objectivity,” Journal of Consumer Research (18:3), 1991, pp. 243-250.

Lewis, G. 2007. Asymmetric Information, Adverse Selection and Seller Disclosure: The Case of eBay Motors, Harvard University, Working Paper, Harvard University.

Ljung, G., and Box, G. “On a Measure of Lack of Fit in Time Series Models”, Biometrika (65), 297-303, 1978.

Nagler, M., and Osgood, D. “A Lemons "Mirage”: Erroneous Perceptions of Asymmetric Information In The Market For Arizona Ranchettes,” Mountain Plains Journal of Business and Economics, General Research, Volume 7, 2006.

Overby, E., "The Adverse Selection Implications of Companion Electronic Markets: An Investigation in the Wholesale Automotive Industry,” Working paper, Georgia Tech, 2008.

Pavlou, P. A., and Dimoka, A. "The Nature and Role of Feedback Text Comments in Online Marketplaces: Implications for Trust Building, Price Premiums, and Seller Differentiation,” Information Systems Research (17:4), 2006, pp. 391-412.

Pavlou, P.A., Liang, H., and Xue, Y. "Understanding and Mitigating Uncertainty in Online Exchange Relationships: A Principal Agent Perspective,” MIS Quarterly (31: 2), 2006, pp 1-32.

Perrault, W., and Leigh, L. "Reliability of Nominal Data Based on Qualitative Judgments,” Journal of Marketing Research (26:2), 1989, pp. 135-148.

Porter, R., and Sattler, P. "Patterns of Trade in the Market for Used Durables: Theory and Evidence," NBER Working Paper no. 7149, 1999, Cambridge.

Resnick, P., Zeckhauser, R., Swanson, J. and Lockwood, K. “The Value of Reputation on eBay: A Controlled Experiment,” Experimental Economics (9:2), 2006, pp. 79-101.

Roodman, D. 2006. "How to do Xtabond2: An Introduction to Difference and System GMM in Stata," Center for Global Development Working Paper No. 103, Available at SSRN.

Schneider, H. "Estimating the Effects of Adverse Selection in Used Car Markets,” Working Paper, Cornell University, 2006.

Shapiro, C. "Premiums for High Quality Products as Returns to Reputations," Quarterly Journal of Economics 98, 1983, 659-679.

Sirmans, C.F., Turnbull, G., and Dombrow, J. “Quick House Sales: Seller Mistake or Luck?” Journal of Housing Economics, 4, 230-243, 1995.

Stolyarov, D. “Turnover of Used Durables in a Stationary Equilibrium: Are Older Goods Traded More?” Journal of Political Economy (110: 6), 2002, pp. 1390-1413.

Villas-Boas, J., Winer, R. “Endogeneity in Brand Choice Models,” Management Science 45(10), 1999 1324-1338.

Weber, R. P. 1990. Basic Content Analysis. Sage Publications, London, UK.

Windmeijer, F. "A Finite Sample Correction for the Variance of Linear Efficient Two-step GMM Estimators,” Journal of Econometrics 126(1), 2005, pp 25-51.

Wolf, J., and Muhanna, W. "Adverse Selection and Reputation Systems in Online Auctions: Evidence from eBay Motors,” Proceedings of the 2005 ICIS, December 2005.

Wooldridge, J. “Econometric Analysis of Cross Section and Panel Data,” Cambridge, MIT Press, 2002.

Yamagishi, T., and Matsuda, M. “Improving the Lemons’ Market with a Reputation System: An Experimental Study of Internet Auctioning”, Working Paper, Hokkaido University, 2004. 


\begin{tabular}{|c|c|}
\hline Variable & Description \\
\hline Manufacturer Price & Manufacturer's price for a new product on Amazon's new good market. \\
\hline Sale Price & Final list price at which the used-good transaction occurred \\
\hline Condition & $\begin{array}{l}\text { Product condition as listed by the seller ranging from 1(lowest } \\
\text { condition) to } 6 \text { (highest condition). }\end{array}$ \\
\hline Seller Rating & $\begin{array}{c}\text { Seller's average numeric reputations score ranging from 1(lowest } \\
\text { rating) to } 5 \text { (highest rating). }\end{array}$ \\
\hline Life & The total number of lifetime ratings the seller has received. \\
\hline Competitors & Number of competing offers at any given time for a product. \\
\hline Sale Time & Number of days it took for a product to be sold after being listed. \\
\hline Trade Volume & Number of used goods of a given product sold by a seller per week. \\
\hline Unreliability & Brand unreliability rankings imputed from Consumer Reports. \\
\hline Offer Position & Position of the used-good offer on the screen ranging from 1 to 25 . \\
\hline PLife & The proportion of positive ratings the seller has received. \\
\hline NLife & The proportion of negative ratings the seller has received. \\
\hline $\begin{array}{l}\text { Seller Service Related } \\
\text { Rating }\end{array}$ & $\begin{array}{c}\text { Dummy indicating whether the feedback had comments about the seller } \\
\text { service quality. }\end{array}$ \\
\hline $\begin{array}{l}\text { Product Condition } \\
\text { Related Rating }\end{array}$ & $\begin{array}{c}\text { Dummy indicating whether the feedback had comments about the } \\
\text { product condition. }\end{array}$ \\
\hline High Condition & Dummy indicating a product with condition equal to 5 and above. \\
\hline Low Reputation & Dummy indicating a seller with average numeric reputation less than 4. \\
\hline Price Decline & $\begin{array}{l}\text { Ratio of difference between the new good price and the used good price } \\
\text { (sale price) to the new good price. }\end{array}$ \\
\hline
\end{tabular}

Table 1: Description of Variables 


\begin{tabular}{l|llllll}
\hline Variable & Obs. & Mean & Std. Dev. & Min & Median & Max \\
\hline Manufacturer Price & 78287 & 599.59 & 245.03 & 29.61 & 549.99 & 2298.99 \\
Sale Price & 78287 & 262.56 & 161.32 & 0.99 & 229.99 & 1049.99 \\
Condition & 78287 & 5.09 & 1.3 & 1 & 5 & 6 \\
Seller Rating & 66076 & 4.46 & 0.5 & 1 & 4.5 & 5 \\
Life & 66076 & 1232.66 & 11402.77 & 1 & 113 & 261610 \\
Competitors & 78287 & 11.65 & 7.48 & 1 & 11 & 26 \\
Sale Time & 78287 & 13.21 & 1.58 & 6 & 10 & 11 \\
Trade Volume & 78287 & 0.479 & 0.303 & 1 & 1 & 3 \\
Unreliability & 78287 & 5.8 & 2.27 & 1 & 7 & 9 \\
Price Decline & 78287 & 0.52 & 0.29 & 0 & 0.54 & 0.99 \\
Offer Position & 78287 & 12.48 & 1.54 & 1 & 12 & 15 \\
PLife & 66076 & 86.24 & 15.12 & 1 & 89 & 100 \\
NLife & 66076 & 10.13 & 12.68 & 1 & 8 & 100 \\
High Condition & 78072 & 0.75 & 0.43 & 0 & 1 & 1 \\
Low Reputation & 66076 & 0.036 & 0.19 & 0 & 0 & 1 \\
Trend & 78287 & 4.26 & 0.19 & 2.39 & 2.95 & 4.45 \\
\hline
\end{tabular}

Table 2: Descriptive statistics for PDAs. The column entitled “Observations” includes all sellercompetitor pairs at the time of a transaction. The total number of actual transactions across all sellers in the dataset was 11708. Note that some sellers who were new to the market did not have any reputation score which is reflected in fewer observations for the seller reputation related variables.

\begin{tabular}{l|llllll}
\hline Variable & Obs. & Mean & Std. Dev. & Min & Median & Max \\
\hline Manufacturer Price & 163292 & 1351.52 & 1068.84 & 82.78 & 1007.71 & 7999.99 \\
Sale Price & 163292 & 415.14 & 328.89 & 0.88 & 349.99 & 7999.99 \\
Condition & 163292 & 5.74 & 0.84 & 1 & 6 & 6 \\
Seller Rating & 135030 & 4.42 & 0.42 & 1 & 4.4 & 5 \\
Life & 135030 & 2082.85 & 13180.22 & 1 & 112 & 261565 \\
Competitors & 163292 & 18.97 & 10.65 & 1 & 18 & 40 \\
Sale Time & 163292 & 13.18 & 1.68 & 8 & 11 & 12 \\
Trade Volume & 163292 & 0.578 & 0.458 & 1 & 1 & 3 \\
Unreliability & 163292 & 6.1 & 1.6 & 1 & 7 & 9 \\
Price Decline & 163292 & 0.59 & 0.28 & 0 & 0.64 & 0.99 \\
Offer Position & 163292 & 4.5 & 2.68 & 1 & 4 & 9 \\
PLife & 135030 & 83.51 & 13.3 & 1 & 82 & 100 \\
NLife & 135030 & 13.43 & 37.96 & 1 & 14 & 3985 \\
High Condition & 163292 & 0.94 & 0.23 & 0 & 1 & 1 \\
Low Reputation & 135030 & 0.03 & 0.17 & 0 & 0 & 1 \\
Trend & 163292 & 4.31 & 0.21 & 2.14 & 3.15 & 4.54 \\
\hline
\end{tabular}

Table 3: Descriptive statistics for digital cameras. The column entitled "Observations” includes all sellercompetitor pairs at the time of a transaction. The total number of actual transactions across all sellers in the dataset was 14172. Note that some sellers who were new to the market did not have any reputation score which is reflected in fewer observations for the seller reputation related variables. 


\begin{tabular}{l|llllll}
\hline Variable & Obs. & Mean & Std. Dev. & Min & Median & Max \\
\hline Manufacturer Price & 67910 & 467.61 & 207.45 & 35.02 & 329.49 & 499.95 \\
Sale Price & 67910 & 162.93 & 126.96 & 1 & 140.8 & 499.95 \\
Condition & 67910 & 5.62 & 0.99 & 1 & 6 & 6 \\
Seller Rating & 62017 & 4.46 & 0.44 & 1 & 4.5 & 5 \\
Life & 62017 & 1310.58 & 8836.42 & 1 & 138 & 277616 \\
Competitors & 67910 & 18.78 & 11.08 & 1 & 13 & 41 \\
Sale Time & 67910 & 13.47 & 1.59 & 5 & 9 & 11 \\
Trade Volume & 67910 & 1.01 & 0.91 & 1 & 1 & 3 \\
Unreliability & 67910 & 2.45 & 1.45 & 1 & 2 & 6 \\
Price Decline & 67910 & 0.67 & 0.28 & 0 & 0.77 & 0.99 \\
Offer Position & 67910 & 4.451 & 2.56 & 1 & 4 & 9 \\
PLife & 62017 & 84.19 & 14.33 & 1 & 72 & 100 \\
NLife & 62017 & 12.52 & 13.47 & 1 & 22 & 100 \\
High Condition & 67910 & 0.93 & 0.25 & 0 & 1 & 1 \\
Low Reputation & 62017 & 0.03 & 0.18 & 0 & 0 & 1 \\
Trend & 67910 & 4.12 & 0.29 & 2.59 & 3.15 & 4.65 \\
\hline
\end{tabular}

Table 4: Descriptive statistics for audio players. The column entitled “Observations” includes all sellercompetitor pairs at the time of a transaction. The total number of actual transactions across all sellers in the dataset was 14463 . Note that some sellers who were new to the market did not have any reputation score which is reflected in fewer observations for the seller reputation related variables.

\begin{tabular}{l|llllll}
\hline Variable & Obs. & Mean & Std. Dev. & Min & Median & Max \\
\hline Manufacturer Price & 105350 & 1486.73 & 617.96 & 649.99 & 74.88 & 1999.99 \\
Sale Price & 105350 & 988.87 & 397.89 & 502.57 & 9.24 & 1999.99 \\
Condition & 105350 & 4.36 & 1.33 & 1 & 3 & 6 \\
Seller Rating & 101971 & 4.7 & 0.23 & 2.7 & 4.7 & 5 \\
Life & 101971 & 6209 & 16025.72 & 1 & 2147 & 272044 \\
Competitors & 105350 & 6.16 & 3.53 & 1 & 3 & 15 \\
Sale Time & 105350 & 12.71 & 1.88 & 10 & 12 & 16 \\
Trade Volume & 105350 & 0.97 & 0.72 & 1 & 1 & 2 \\
Unreliability & 105350 & 6.62 & 1.74 & 1 & 5 & 9 \\
Price Decline & 105350 & 0.968 & 0.11 & 0 & 0.87 & 0.99 \\
Offer Position & 105350 & 11.378 & 0.573 & 1 & 11 & 12 \\
PLife & 101971 & 92.74 & 7.88 & 1 & 82 & 100 \\
NLife & 101971 & 4.76 & 6.06 & 1 & 5 & 100 \\
High Condition & 105350 & 0.374 & 0.48 & 0 & 0 & 1 \\
Low Reputation & 101971 & 0.02 & 0.14 & 0 & 0 & 1 \\
Trend & 105350 & 4.36 & 0.22 & 2.51 & 2.95 & 4.84 \\
\hline
\end{tabular}

Table 5: Descriptive statistics for laptops. The column entitled “Observations” includes all sellercompetitor pairs at the time of a transaction. The total number of actual transactions across all sellers in the dataset was 18676. Note that some sellers who were new to the market did not have any reputation score which is reflected in fewer observations for the seller reputation related variables. 


\begin{tabular}{c|cccc}
\hline Rank & Audio Players & Digital Cameras & Laptops & PDAs \\
\hline 1 & Sony & Sony & Apple & Palm \\
2 & Panasonic & Panasonic & IBM & Asus \\
3 & Apple & Canon & Toshiba & HP \\
4 & Phillips & Kodak & Dell & Dell \\
5 & Toshiba & Minolta & Gateway & Sony \\
6 & Other Brands & Toshiba & HP & Garmin \\
7 & & Vivitar & Compaq & Toshiba \\
8 & & Samsung & Sony & Sharp \\
9 & & Other Brands & Other Brands & Other Brands \\
\hline
\end{tabular}

Table 6: Reliability ranks for different brands in the dataset. These rankings are based directly on the "Overall Scores" published in Consumer Reports that rate and rank different brands based on their repair history. 
Effect of Seller and Product Characteristics on Sale Time for PDAs ( $\mathrm{N}=11708)$

\begin{tabular}{|c|c|c|c|c|c|}
\hline \multirow[b]{2}{*}{ Variable } & \multicolumn{4}{|c|}{ OLS } & \multirow{2}{*}{$\frac{2 S L S}{(5)}$} \\
\hline & (1) & (2) & (3) & (4) & \\
\hline Log[Sale Price $]$ & $0.01^{* *}(.0004)$ & $0.014^{* *}(0.004)$ & $0.015^{* *}(0.004)$ & $0.025^{* *}(0.01)$ & $0.035^{* *}(0.016)$ \\
\hline Log[Seller Rating] & $0.16^{* * *}(0.01)$ & $0.06^{* * *}(0.02)$ & & & \\
\hline Log[Life] & $0.09^{* * *}(0.001)$ & & $0.1^{* * *}(0.001)$ & $0.16^{* * *}(0.001)$ & $0.16^{* * *}(0.001)$ \\
\hline Log[PLife] & & $0.1^{* * *}(0.01)$ & & & \\
\hline Log[NLife] & & $-0.06^{* * *}(0.01)$ & & & \\
\hline Log[Condition] & $0.01(0.01)$ & $0.001(0.001)$ & & $0.003(0.002)$ & $0.004(0.003)$ \\
\hline Log[Competitors $]$ & $-0.002(0.003)$ & $-0.002(0.003)$ & $-0.0025(0.003)$ & $-0.003(0.003)$ & $-0.005(0.005)$ \\
\hline Log[Offer Position] & $-0.006^{* * *}(0.0001)$ & $-0.005^{* * *}(0.0001)$ & $-0.005^{* * *}(0.0001)$ & $-0.004^{* * *}(0.0001)$ & $-0.005^{* * *}(0.0002)$ \\
\hline High Condition & & & $0.25(0.2)$ & & \\
\hline Low Reputation & & & $-0.55^{* * *}(0.12)$ & & \\
\hline High Condition x Low Reputation & & & $0.5(0.3)$ & & \\
\hline Log[Seller Service Related Rating] & & & & $0.43^{* * *}(0.01)$ & $0.55^{* * *}(0.02)$ \\
\hline Log[Product Condition Related Rating] & & & & $0.1^{* * *}(0.01)$ & $0.12^{* * *}(0.02)$ \\
\hline Trend & & & & & $0.075(0.1)$ \\
\hline $\mathrm{R}^{2}$ (within) & 0.06 & 0.02 & 0.06 & 0.07 & 0.07 \\
\hline $\mathrm{R}^{2}$ (with Fixed Effects) & 0.66 & 0.66 & 0.68 & 0.74 & \\
\hline
\end{tabular}

Table 7: The dependent variable is Log of Sale Time. All models use OLS with product-seller fixed effects. Robust standard errors are in parenthesis. *** and ** denote significance at $1 \%$ and $5 \%$, respectively. Column (2) splits the Life variable into positives and negative. Column (3) shows the interaction effect between high condition and low reputation. Column (4) splits the seller rating variable into two components of seller service related rating and product condition related rating based on the content analysis. Column (5) uses 2SLS to instrument for sale price using lagged values of the same variable and search volume data from 'Google Trends' to control for correlated demand shocks. 
Effect of Seller and Product Characteristics on Sale Time for Digital Cameras ( $N=14172)$

\begin{tabular}{|c|c|c|c|c|c|}
\hline \multirow[b]{2}{*}{ Variable } & \multicolumn{4}{|c|}{ OLS } & \multirow{2}{*}{$\begin{array}{c}\text { 2SLS } \\
\text { (5) }\end{array}$} \\
\hline & (1) & (2) & (3) & (4) & \\
\hline Log[Sale Price $]$ & $0.023^{* * *}(0.006)$ & $0.011^{* * *}(0.004)$ & $0.024^{* * *}(0.006)$ & $0.03^{* * *}(0.006)$ & $0.044^{* * *}(0.01)$ \\
\hline Log[Seller Rating] & $0.18^{* * *}(0.007)$ & $0.18^{* * *}(0.007)$ & & & \\
\hline Log[Life $]$ & $0.51^{* * *}(0.02)$ & & $0.5^{* * *}(0.02)$ & $0.6^{* * *}(0.02)$ & $0.72^{* * *}(0.04)$ \\
\hline Log[PLife] & & $0.21^{* * *}(0.01)$ & & & \\
\hline Log[NLife $]$ & & $-0.1^{* * *}(0.01)$ & & & \\
\hline Log[Condition] & $0.04(0.024)$ & $0.035^{* * *}(0.01)$ & & $0.03^{* * *}(0.01)$ & $0.044^{* * *}(0.02)$ \\
\hline Log[Competitors] & $-0.01^{* * *}(.001)$ & $-0.01^{* * *}(0.001)$ & $-0.01^{* * *}(0.001)$ & $-0.015^{* * *}(0.001)$ & $-0.02^{* * *}(0.002)$ \\
\hline Log[Offer Position] & $-0.004^{* * *}(0.0001)$ & $-0.006^{* * *}(0.0001)$ & $-0.005^{* * *}(0.0001)$ & $-0.005^{* * *}(0.0001)$ & $-0.006^{* * *}(0.0001)$ \\
\hline High Condition & & & $0.15(0.1)$ & & \\
\hline Low Reputation & & & $-0.6^{* * *}(0.21)$ & & \\
\hline High Condition xLow Reputation & & & $0.2(0.15)$ & & \\
\hline Log[Seller Service Related Rating] & & & & $0.35^{* * *}(0.01)$ & $0.52^{* * * *}(0.02)$ \\
\hline Log[Product Condition Related Rating] & & & & $0.12^{* * *}(0.01)$ & $0.17^{* * *}(0.02)$ \\
\hline Trend & & & & & $0.05(0.1)$ \\
\hline $\mathrm{R}^{2}$ (within) & 0.08 & 0.07 & 0.08 & 0.09 & 0.1 \\
\hline $\mathrm{R}^{2}$ (with Fixed Effects) & 0.78 & 0.78 & 0.79 & 0.86 & \\
\hline
\end{tabular}

Table 8: The dependent variable is Log of Sale Time. All models use OLS with product-seller fixed effects. Robust standard errors are in parenthesis. $* * *$ and ** denote significance at $1 \%$ and $5 \%$, respectively. Column (2) splits the Life variable into positives and negative. Column (3) shows the interaction effect between high condition and low reputation. Column (4) splits the seller rating variable into two components of seller service related rating and product condition related rating based on the content analysis. Column (5) uses 2SLS to instrument for sale price using lagged values of the same variable and search volume data from 'Google Trends' to control for correlated demand shocks. 
Effect of Seller and Product Characteristics on Sale Time for Audio Players ( $\mathrm{N}=14463)$

\begin{tabular}{|c|c|c|c|c|c|}
\hline \multirow[b]{2}{*}{ Variable } & \multicolumn{4}{|c|}{ OLS } & \multirow{2}{*}{$\begin{array}{c}\text { 2SLS } \\
\text { (5) }\end{array}$} \\
\hline & (1) & (2) & (3) & (4) & \\
\hline Log[Sale Price $]$ & $0.24^{* * *}(0.01)$ & $0.25^{* * *}(0.01)$ & $0.18^{* * *}(0.01)$ & $0.32^{* * *}(0.01)$ & $0.47^{* * *}(0.02)$ \\
\hline Log[Life $]$ & $0.04^{* * *}(0.002)$ & & $0.03^{* * *}(0.002)$ & $0.052^{* * *}(0.002)$ & $0.07^{* * *}(0.003)$ \\
\hline Log[PLife] & & $0.03^{* * *}(0.001)$ & & & \\
\hline Log[NLife] & & $-0.04^{* * * *}(0.001)$ & & & \\
\hline Log[Competitors] & $-0.002^{* * *}(0.0002)$ & $-0.002^{* * * *}(0.0002)$ & $-0.002^{* * *}(0.0002)$ & $-0.002^{* * *}(0.0002)$ & $-0.003^{* * *}(0.0003)$ \\
\hline Log[Offer Position] & $-0.003^{* * *}(0.0001)$ & $-0.002^{* * * *}(0.0001)$ & $-0.003^{* * *}(0.0001)$ & $-0.004^{* * * *}(0.0001)$ & $-0.004^{* * *}(0.0002)$ \\
\hline High Condition & & & $0.92^{* * *}(0.11)$ & & \\
\hline Low Reputation & & & $-0.56^{* * *}(0.12)$ & & \\
\hline High Condition xLow Reputation & & & $0.04(0.1)$ & & \\
\hline $\mathrm{R}^{2}$ (within) & 0.11 & 0.14 & 0.14 & 0.15 & 0.15 \\
\hline $\mathrm{R}^{2}$ (with Fixed Effects) & 0.81 & 0.82 & 0.82 & 0.87 & \\
\hline
\end{tabular}

Table 9: The dependent variable is Log of Sale Time. All models use OLS with product-seller fixed effects. Robust standard errors are in parenthesis. ${ }^{* * *}$ and ** denote significance at $1 \%$ and 5\%, respectively. Column (2) splits the Life variable into positives and negative. Column (3) shows the interaction effect between high condition and low reputation. Column (4) splits the seller rating variable into two components of seller service related rating and product condition related rating based on the content analysis. Column (5) uses 2SLS to instrument for sale price using lagged values of the same variable and search volume data from 'Google Trends' to control for correlated demand shocks. 
Effect of Seller and Product Characteristics on Sale Time for Laptops $(\mathrm{N}=18676)$

\begin{tabular}{|c|c|c|c|c|c|}
\hline \multirow[b]{2}{*}{ Variable } & \multicolumn{4}{|c|}{ OLS } & \multirow{2}{*}{$\begin{array}{c}\text { 2SLS } \\
(5)\end{array}$} \\
\hline & (1) & (2) & (3) & (4) & \\
\hline Log[Sale Price] & $0.03^{* * *}(0.001)$ & $0.01^{* * *}(0.001)$ & $0.03^{* * *}(0.001)$ & $0.045^{* * *}(0.001)$ & $0.066^{* * *}(0.002)$ \\
\hline Log[Seller Rating] & $0.72^{* * *}(0.01)$ & $0.79^{* * *}(0.01)$ & & & \\
\hline Log[Life $]$ & $0.1^{* * *}(0.001)$ & & $0.11^{* * *}(0.001)$ & $0.21^{* * *}(0.001)$ & $0.28^{* * *}(0.001)$ \\
\hline Log[PLife] & & $0.1^{* * *}(0.001)$ & & & \\
\hline Log[NLife] & & $-0.07^{* * *}(0.001)$ & & & \\
\hline Log[Condition] & $0.03^{* * *}(0.001)$ & $0.03^{* * *}(0.001)$ & & $0.035^{* * *}(0.001)$ & $0.048^{* * *}(0.002)$ \\
\hline Log[Competitors] & $0.0006^{* *}(0.0003)$ & $0.001^{* *}(0.0003)$ & $0.0006^{* *}(0.0003)$ & $0.001^{* * *}(0.0003)$ & $0.001^{* * *}(0.0005)$ \\
\hline Log[Offer Position] & $-0.001^{* * *}(0.0001)$ & $-0.001^{* * *}(0.0001)$ & $-0.001^{* * *}(0.0001)$ & $-0.001^{* * *}(0.0001)$ & $-0.001^{* * *}(0.0002)$ \\
\hline High Condition & & & $0.5^{* * *}(0.01)$ & & \\
\hline Low Reputation & & & $-0.16^{* * *}(0.1)$ & & \\
\hline High Condition x Low Reputation & & & $0.06^{* * *}(0.01)$ & & \\
\hline Log[Seller Service Related Rating] & & & & $0.81^{* * *}(0.01)$ & $1.15^{* * *}(0.02)$ \\
\hline Log[Product Condition Related Rating] & & & & $0.3^{* * *}(0.01)$ & $0.42^{* * *}(0.02)$ \\
\hline Trend & & & & & $0.09(0.115)$ \\
\hline $\mathrm{R}^{2}$ (within) & 0.18 & 0.19 & 0.19 & 0.21 & 0.21 \\
\hline $\mathrm{R}^{2}$ (with Fixed Effects) & 0.81 & 0.81 & 0.82 & 0.88 & \\
\hline
\end{tabular}

Table 10: The dependent variable is Log of Sale Time. All models use OLS with product-seller fixed effects. Robust standard errors are in parenthesis. ${ }^{* * *}$ and ** denote significance at $1 \%$ and $5 \%$, respectively. Column (2) splits the Life variable into positives and negative. Column (3) shows the interaction effect between high condition and low reputation. Column (4) splits the seller rating variable into two components of seller service related rating and product condition related rating based on the content analysis. Column (5) uses 2SLS to instrument for sale price using lagged values of the same variable and search volume data from 'Google Trends' to control for correlated demand shocks. 
Relationship Between Trade Volume, Unreliability and Price Decline for Digital Cameras ( $=472)$

\begin{tabular}{|c|c|c|c|c|c|}
\hline & \multicolumn{2}{|c|}{ OLS } & \multicolumn{2}{c|}{ 2SLS } & GMM \\
\hline Variable & $\mathbf{( 1 )}$ & $\mathbf{( 2 )}$ & $\mathbf{( 3 )}$ & $\mathbf{( 4 )}$ & $\mathbf{( 5 )}$ \\
\hline Log[Competitors] & $0.01^{* * *}(0.001)$ & $0.012^{* * *}(0.001)$ & $0.01^{* * *}(0.002)$ & $0.012^{* * *}(0.002)$ & $0.01^{* * *}(0.001)$ \\
\hline Log[Rating] & $-0.44^{* * *}(0.02)$ & $-0.44^{* * *}(0.02)$ & $-0.53^{* * *}(0.043)$ & $-0.53^{* * *}(0.043)$ & $-0.35^{* * *}(0.014)$ \\
\hline Log[Life] & $-0.025^{* * *}(0.006)$ & $-0.025^{* * *}(0.006)$ & $-0.03^{* * *}(0.011)$ & $-0.025^{* * *}(0.011)$ & $-0.02^{* * *}(0.006)$ \\
\hline Log[Condition] & $-0.035^{* * *}(0.01)$ & $-0.035^{* * *}(0.01)$ & $-0.048^{* * *}(0.021)$ & $-0.048^{* * *}(0.021)$ & $-0.025^{* * *}(0.01)$ \\
\hline Log[Trade Volume] & $-0.125^{* * *}(0.01)$ & $-0.13^{* * *}(0.01)$ & $-0.18^{* * *}(0.025)$ & $-0.18^{* * *}(0.025)$ & $-0.1^{* * *}(0.01)$ \\
\hline Unreliability & $0.33^{* * *}(0.01)$ & $0.35^{* * *}(0.01)$ & $0.42^{* * *}(0.015)$ & $0.45^{* * *}(0.015)$ & $0.27^{* * *}(0.01)$ \\
\hline Log[TradeVolume]*Unreliability & & $-0.041^{* * *}(0.001)$ & & $-0.053^{* * *}(0.002)$ & $-0.034^{* * *}(0.001)$ \\
\hline Lagged Price Decline & & & & $0.72^{* * *}(0.21)$ \\
\hline Constant & $-2.2^{* * *}(0.1)$ & $-2.45^{* * *}(0.08)$ & $-2.6^{* * *}(0.1)$ & $-2.85^{* * *}(0.1)$ & $-1.05^{* * *}(0.1)$ \\
\hline $\mathrm{R}^{2}$ (within) & 0.02 & 0.02 & 0.02 & 0.02 & \\
\hline
\end{tabular}

Table 11: The dependent variable is Log of Price Decline. Estimates in columns (1) and (2) are based on OLS with model-seller fixed effects. Robust standard errors are in parenthesis. ${ }^{* * *}$ and $* *$ denote significance at $1 \%$ and $5 \%$, respectively. Columns (3) and (4) use 2SLS to instrument for trade volume using lagged values of the same variable.

Column (5) uses the efficient system GMM estimator based on the Arellano-Bover (1995)/Blundell-Bond (1998) specifications. Standard errors are corrected using the two-step covariance matrix derived by Windmeijer (2005). Time dummies are included. The Hansen J test for overidentifying restrictions confirms the validity of the instruments since the null hypothesis cannot be rejected. The Arellano-Bond test, AR (2) in differences shows no second-order serial correlation in errors. 
Relationship Between Trade Volume, Unreliability and Price Decline for PDAs (N = 292)

\begin{tabular}{|c|c|c|c|c|c|}
\hline & \multicolumn{2}{|c|}{ OLS } & \multicolumn{2}{|c|}{ 2SLS } & GMM \\
\hline Variable & $\mathbf{( 1 )}$ & $\mathbf{( 2 )}$ & $\mathbf{( 3 )}$ & $\mathbf{( 4 )}$ \\
\hline Log[Competitors] & $0.02^{* * *}(0.003)$ & $0.02^{* * *}(0.003)$ & $0.02^{* * *}(0.005)$ & $0.02^{* * *}(0.005)$ & $0.016^{* * * *}(0.003)$ \\
\hline Log[Rating] & $-0.51^{* * *}(0.16)$ & $-0.51^{* * *}(0.16)$ & $-0.64^{* * *}(0.26)$ & $-0.64^{* * *}(0.26)$ & $-0.42^{* *}(0.16)$ \\
\hline Log[Life] & $0.1^{* * *}(0.02)$ & $0.1^{* * *}(0.02)$ & $0.15^{* * *}(0.042)$ & $0.15^{* * *}(0.042)$ & $0.07^{* * *}(0.03)$ \\
\hline Log[Condition] & $-0.04^{* * *}(0.01)$ & $-0.04^{* * *}(0.01)$ & $-0.055^{* * *}(0.015)$ & $-0.055^{* * *}(0.015)$ & $-0.04^{* * *}(0.01)$ \\
\hline Log[Trade Volume] & $-0.08^{* * *}(0.02)$ & $-0.078^{* * *}(0.02)$ & $-0.11^{* * *}(0.033)$ & $-0.11^{* * *}(0.033)$ & $-0.05^{* * *}(0.02)$ \\
\hline Unreliability & $0.05^{* * *}(0.021)$ & $0.055^{* * *}(0.022)$ & $0.062^{* * *}(0.021)$ & $0.066^{* * *}(0.022)$ & $0.035^{* * *}(0.01)$ \\
\hline Log[TradeVolume]*Unreliability & & $0.001(0.002)$ & & $0.001(0.002)$ & $0.001(0.002)$ \\
\hline Lagged Price Decline & & & & $0.64^{* * *}(0.26)$ \\
\hline Constant & $-6.1^{* * *}(0.3)$ & $-7.4^{* * *}(0.28)$ & $-4.5^{* * *}(0.3)$ & $-5.1^{* * *}(0.28)$ & $-6.9^{* * * *}(0.3)$ \\
\hline $\mathrm{R}^{2}$ (within) & 0.02 & 0.02 & 0.02 & 0.02 & \\
\hline
\end{tabular}

Table 12: The dependent variable is Log of Price Decline. Estimates in columns (1) and (2) are based on OLS with model-seller fixed effects. Robust standard errors are in parenthesis. ${ }^{* * *}$ and ${ }^{* *}$ denote significance at $1 \%$ and $5 \%$, respectively. Columns (3) and (4) use 2SLS to instrument for trade volume using lagged values of the same variable.

Column (5) uses the efficient system GMM estimator based on the Arellano-Bover (1995)/Blundell-Bond (1998) specifications. Standard errors are corrected using the two-step covariance matrix derived by Windmeijer (2005). Time dummies are included. The Hansen J test for overidentifying restrictions confirms the validity of the instruments since the null hypothesis cannot be rejected. The Arellano-Bond test, AR (2) in differences shows no second-order serial correlation in errors. 
Relationship Between Trade Volume, Unreliability and Price Decline for Audio Players ( $\mathbf{N}=481)$

\begin{tabular}{|c|c|c|c|c|c|}
\hline \multirow[b]{2}{*}{ Variable } & \multicolumn{2}{|c|}{ OLS } & \multicolumn{2}{|c|}{ 2SLS } & \multirow{2}{*}{$\begin{array}{c}\text { GMM } \\
\text { (5) }\end{array}$} \\
\hline & (1) & $(2)$ & (3) & $(4)$ & \\
\hline Log[Competitors] & $0.01^{* * * *}(0.001)$ & $0.01^{* * *}(0.001)$ & $0.014^{* * *}(0.001)$ & $0.014^{* * *}(0.001)$ & $0.007^{* * *}(0.001)$ \\
\hline Log[Rating] & $-0.05^{* * *}(0.01)$ & $-0.05^{* * *}(0.01)$ & $-0.072^{* * *}(0.02)$ & $-0.072^{* * *}(0.02)$ & $-0.04^{* * *}(0.01)$ \\
\hline Log[Life] & $-0.02^{* * *}(0.001)$ & $-0.02^{* * *}(0.001)$ & $-0.033^{* * *}(0.002)$ & $-0.033^{* * *}(0.002)$ & $-0.017^{* * *}(0.001)$ \\
\hline Log[Condition] & $-0.01^{* * *}(0.001)$ & $-0.01^{* * *}(0.001)$ & $-0.014^{* * *}(0.0015)$ & $-0.014^{* * *}(0.0015)$ & $-0.008^{* * *}(0.001)$ \\
\hline Log[Trade Volume] & $-0.02^{* * *}(0.001)$ & $-0.02^{* * *}(0.001)$ & $-0.025^{* * *}(0.002)$ & $-0.025^{* * *}(0.002)$ & $-0.01^{* * *}(0.001)$ \\
\hline Unreliability & $-0.025^{* * *}(0.002)$ & $-0.03^{* * *}(0.002)$ & $-0.031^{* * *}(0.003)$ & $-0.038^{* * *}(0.003)$ & $-0.016^{* * *}(0.002)$ \\
\hline Log[TradeVolume]*Unreliability & & $0.04^{* * *}(0.001)$ & & $0.055^{* * *}(0.002)$ & $0.028^{* * *}(0.001)$ \\
\hline Lagged Price Decline & & & & & $0.12^{* * *}(0.1)$ \\
\hline Constant & $0.85^{* * *}(0.1)$ & $0.5^{* * *}(0.1)$ & $1.185^{* * *}(0.22)$ & $1.15^{* * *}(0.2)$ & $0.65^{* * *}(0.1)$ \\
\hline $\mathrm{R}^{2}$ (within) & 0.03 & 0.03 & 0.03 & 0.03 & \\
\hline
\end{tabular}

Table 13: The dependent variable is Log of Price Decline. Estimates in columns (1) and (2) are based on OLS with model-seller fixed effects. Robust standard errors are in parenthesis. ${ }^{* * *}$ and $* *$ denote significance at $1 \%$ and $5 \%$, respectively. Columns (3) and (4) use 2SLS to instrument for trade volume using lagged values of the same variable.

Column (5) uses the efficient system GMM estimator based on the Arellano-Bover (1995)/Blundell-Bond (1998) specifications. Standard errors are corrected using the two-step covariance matrix derived by Windmeijer (2005). Time dummies are included. The Hansen J test for overidentifying restrictions confirms the validity of the instruments since the null hypothesis cannot be rejected. The Arellano-Bond test, AR (2) in differences shows no second-order serial correlation in errors. 
Relationship Between Trade Volume, Unreliability and Price Decline for Laptops ( $\mathrm{N}=622)$

\begin{tabular}{|c|c|c|c|c|c|}
\hline & \multicolumn{2}{|c|}{ OLS } & \multicolumn{2}{|c|}{ 2SLS } & GMM \\
\hline Variable & $\mathbf{( 1 )}$ & $\mathbf{( 2 )}$ & $\mathbf{( 3 )}$ & $\mathbf{( 4 )}$ & $\mathbf{( 5 )}$ \\
\hline Log[Competitors] & $0.001^{* * *}(0.0002)$ & $0.001^{* * *}(0.0002)$ & $0.0015^{* * *}(0.0002)$ & $0.0015^{* * *}(0.0002)$ & $0.001^{* * *}(0.0002)$ \\
\hline Log[Rating] & $-0.082^{* *}(0.01)$ & $-0.082^{* * *}(0.01)$ & $-0.11^{* * *}(0.015)$ & $-0.11^{* * *}(0.015)$ & $-0.067^{* * * *}(0.01)$ \\
\hline Log[Life] & $0.011^{* * *}(0.001)$ & $0.011^{* * *}(0.001)$ & $0.014^{* * *}(0.002)$ & $0.014^{* * *}(0.002)$ & $0.008^{* * *}(0.002)$ \\
\hline Log[Condition] & $0.072^{* * *}(0.002)$ & $0.072^{* * *}(0.002)$ & $0.1^{* * * *}(0.003)$ & $0.1^{* * *}(0.003)$ & $0.043^{* * *}(0.003)$ \\
\hline Log[Trade Volume] & $-0.056^{* * *}(0.001)$ & $-0.05^{* * *}(0.0005)$ & $-0.074^{* * *}(0.002)$ & $-0.071^{* * *}(0.001)$ & $-0.041^{* * *}(0.001)$ \\
\hline Unreliability & $0.042^{* * *}(0.001)$ & $0.04^{* * *}(0.001)$ & $0.054^{* * *}(0.002)$ & $0.051^{* * *}(0.002)$ & $0.03^{* * *}(0.001)$ \\
\hline Log[TradeVolume]*Unreliability & & $-0.005^{* * *}(0.0001)$ & & $-0.008^{* * *}(0.0002)$ & $-0.004^{* * *}(0.0001)$ \\
\hline Lagged Price Decline & & & & & $0.16^{* * *}(0.05)$ \\
\hline Constant & $-4.5^{* * *}(0.1)$ & $-6.81^{* * *}(0.1)$ & $-6.1^{* * *}(0.21)$ & $-7.2^{* * *}(0.22)$ & $-5.94^{* * *}(0.12)$ \\
\hline $\mathrm{R}^{2}$ (within) & 0.03 & 0.03 & 0.03 & 0.03 & \\
\hline
\end{tabular}

Table 14: The dependent variable is Log of Price Decline. Estimates in columns (1) and (2) are based on OLS with model-seller fixed effects. Robust standard errors are in parenthesis. ${ }^{* * *}$ and ${ }^{* *}$ denote significance at $1 \%$ and $5 \%$, respectively. Columns (3) and (4) use 2SLS to instrument for trade volume using lagged values of the same variable.

Column (5) uses the efficient system GMM estimator based on the Arellano-Bover (1995)/Blundell-Bond (1998) specifications. Standard errors are corrected using the two-step covariance matrix derived by Windmeijer (2005). Time dummies are included. The Hansen J test for overidentifying restrictions confirms the validity of the instruments since the null hypothesis cannot be rejected. The Arellano-Bond test, AR (2) in differences shows no second-order serial correlation in errors. 


\section{Appendix}

\section{Product condition related feedback}

Item was exactly as described. Very pleased.

My box arrived banged up pretty bad with holes and broken foam. There was no bottom to the box.

The back of the unit was smashed in!

Fantastic - received in excellent brand-new condition as promised.

Great product, thanks.

Seller service related feedback

Absolute outstanding service, and extremely fast shipping. I highly recommend this seller to all amazon buyers!!!!!!!

No info available on when it would be available. It took several phone calls and emails to get refund.

Fast shipping, good communication...thanks.

Shipping was unbelievable quick. I would definitely order from them again.

\section{Both product and seller related feedback}

Quick delivery! Camera was exactly as described. Would buy from this seller again.

Fast shipping - arrived exactly as advertised.

Super fast shipping. Excellent item. Perfect transaction. A high quality professional seller. Highly recommended!

Perfect packaging, responsive seller, product works just as described.

Table A1: This table shows some examples of seller service related and product condition related feedback that was posted on Amazon for the sellers in our data. They include both positive and negative comments. Note that some feedback postings can have information about both product and seller. 


\begin{tabular}{|c|c|c|c|}
\hline Price & Condition & Seller Information & Ready to buy? \\
\hline \multirow[t]{6}{*}{$\$ 87.62$} & \multirow[t]{6}{*}{ Used - Like New } & warehouse deals & (E) Add to Cart \\
\hline & & 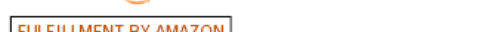 & or \\
\hline & & FULFILLMENT BY AMAZON & (1) Buy with 1-Click ${ }^{2}$ \\
\hline & & $\begin{array}{l}\text { Rating: } \\
\text { (136615 ratings.) } 395 \% \text { positive over the past } 12 \text { months } \\
\text { lifetime ratings. }\end{array}$ & $\begin{array}{c}\text { Ship to: } \\
\end{array}$ \\
\hline & & $\begin{array}{l}\text { Shipping: In Stock. Want it delivered Thursday, July } 3 \text { ? } \\
\text { Order it in the next } 22 \text { hours and } 43 \text { minutes, and choose } \\
\text { One-Day Shipping at checkout. See details. See shipping } \\
\text { rates. See return policy. }\end{array}$ & \\
\hline & & $\begin{array}{l}\text { Comments: Open box unit. Package resealed. All } \\
\text { purchases eligible for Amazon customer service and } 30 \text { day } \\
\text { return policy. }\end{array}$ & \\
\hline \multirow[t]{4}{*}{$\$ 83.50$} & \multirow[t]{4}{*}{ Used - Like New } & Seller: cINCYNOW & Add to Cart \\
\hline & & $\begin{array}{l}\text { Rating: } \\
\text { (925 ratings.) } 3541 \text { lifetime ratings. }\end{array}$ & or \\
\hline & & $\begin{array}{l}\text { Shipping: In Stock. Ships from OH, United States Expedited } \\
\text { shipping available See shipping rates }\end{array}$ & Ship to: \\
\hline & & $\begin{array}{l}\text { Comments: Floor Display Model - Excellent Condition - } \\
\text { Includes Remote Control/Batteries/Instructions (NO Box) - } \\
\text { NOT Refurbished - Ships... ( } \gg \text { more })\end{array}$ & \\
\hline \multirow[t]{7}{*}{$\$ 89.00$} & \multirow[t]{7}{*}{ Used - Like New } & & (-) Add to Cart \\
\hline & & PRICE & or \\
\hline & & BREAKER & (1) Buy with 1-Click ${ }^{2}$ \\
\hline & & & Ship to: \\
\hline & & $\begin{array}{l}\text { Rating: } \\
\text { ( } 2 \text { ratings.) } 2 \text { lifetime ratings. }\end{array}$ & \\
\hline & & $\begin{array}{l}\text { Shipping: In Stock. Expedited shipping available. } \\
\text { International shipping available. See shipping rates. See } \\
\text { return policy. }\end{array}$ & \\
\hline & & Comments: BRAND NEW.ORIGINALBOX. & \\
\hline
\end{tabular}

Figure 1a: Example of product condition disclosures by different sellers on Amazon for a used audio player. In this case, all three used good listings are of the 'Like New' category. The same interface also summarizes the reputation scores of each of the sellers, both in terms of the average rating and the number of feedback postings recorded since inception.

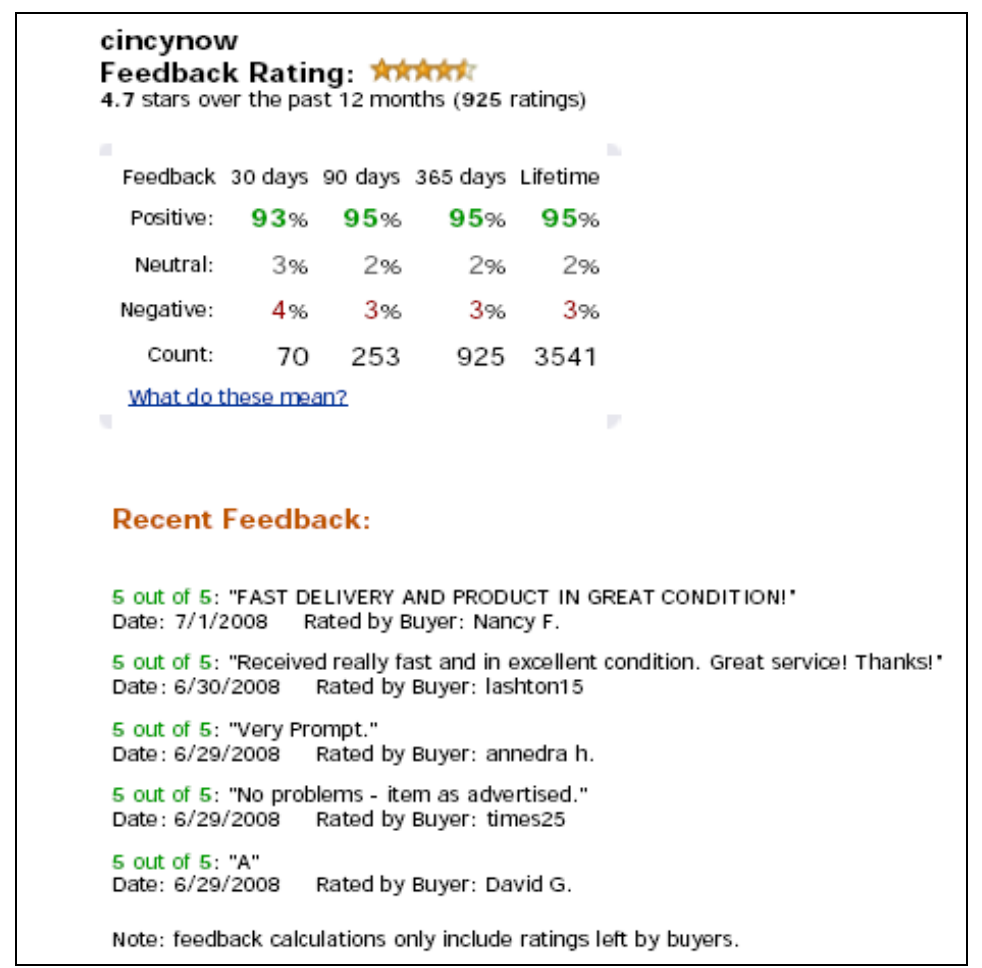

Figure 1b: Fraction of the feedback profile for a seller, as displayed by Amazon. The interface shows the valence and volume of feedback postings as well the actual textual feedback. The first page shows the most recent 5 postings. 
To demonstrate that the absence of information on seller size and inventory does not bias our results, we conduct various robustness checks by classifying sellers into small, medium and large sellers based on the volume of prior recorded transactions. In particular, we designated all sellers with less than 50,000 feedback postings as "small sellers", all sellers with 50,000 to 100,000 postings as "medium sellers" and all sellers with more than 100,000 postings as "large sellers". As seen in Tables A1-A4 below, results from the main specification (model 1 of equation 1 ) are robust to the use of such sub-samples and remain the same qualitatively.

Effect of Seller and Product Characteristics on Sale Time for PDAs

\begin{tabular}{|c|c|c|c|}
\hline Variable & Small Sellers & Medium Sellers & Large Sellers \\
\hline Log[Sale Price] & $0.12^{* *}(0.001)$ & $0.1^{* *}(0.001)$ & $0.05^{* *}(0.001)$ \\
\hline Log[Seller Rating] & $0.22^{* * *}(0.01)$ & $0.2^{* * *}(0.01)$ & $0.06^{* * *}(0.01)$ \\
\hline Log[Life] & $0.19^{* * *}(0.002)$ & $0.23^{* * *}(0.002)$ & $0.1^{* * *}(0.002)$ \\
\hline Log[Condition] & $0.01(0.01)$ & $0.005(0.003)$ & $0.004(0.003)$ \\
\hline Log[Competitors] & $-0.006(0.004)$ & $-0.01(0.008)$ & $-0.006(0.004)$ \\
\hline Log[Offer Position] & $-0.006^{* * *}(0.0001)$ & $-0.006^{* * *}(0.0001)$ & $-0.006^{* * *}(0.0001)$ \\
\hline $\mathrm{R}^{2}$ (with Fixed Effects) & 0.62 & 0.65 & 0.71 \\
\hline
\end{tabular}

Table A1: The dependent variable is Log of Sale Time. All models use OLS with product-seller fixed effects. Robust standard errors are in parenthesis. $* * *$ and $* *$ denote significance at $1 \%$ and $5 \%$, respectively.

Effect of Seller and Product Characteristics on Sale Time for Digital Cameras

\begin{tabular}{|c|c|c|c|}
\hline Variable & Small Sellers & Medium Sellers & Large Sellers \\
\hline Log[Sale Price] & $0.03^{* * *}(0.01)$ & $0.02^{* * *}(0.01)$ & $0.1^{* * *}(0.01)$ \\
\hline Log[Seller Rating] & $0.28^{* * *}(0.01)$ & $0.31^{* * *}(0.02)$ & $0.19^{* * *}(0.02)$ \\
\hline Log[Life] & $0.65^{* * *}(0.04)$ & $0.54^{* * *}(0.05)$ & $0.24^{* * *}(0.06)$ \\
\hline Log[Condition] & $0.04(0.03)$ & $0.052^{* * *}(0.022)$ & $0.044^{* * *}(0.02)$ \\
\hline Log[Competitors] & $-0.02^{* * *}(0.002)$ & $-0.02^{* * *}(0.002)$ & $-0.05^{* * *}(0.004)$ \\
\hline Log[Offer Position] & $-0.004^{* * *}(0.0001)$ & $-0.005^{* * *}(0.0001)$ & $-0.004^{* * *}(0.0001)$ \\
\hline $\mathrm{R}^{2}$ (with Fixed Effects) & 0.73 & 0.71 & 0.71 \\
\hline
\end{tabular}

Table A2: The dependent variable is Log of Sale Time. All models use OLS with product-seller fixed effects. Robust standard errors are in parenthesis. ${ }^{* * *}$ and $* *$ denote significance at $1 \%$ and $5 \%$, respectively. 
Effect of Seller and Product Characteristics on Sale Time for Audio Players

\begin{tabular}{|c|c|c|c|}
\hline Variable & Small Sellers & Medium Sellers & Large Sellers \\
\hline Log[Sale Price] & $0.31^{* * *}(0.012)$ & $0.28^{* * *}(0.012)$ & $0.36^{* * *}(0.012)$ \\
\hline Log[Seller Rating] & $0.29^{* * *}(0.01)$ & $0.32^{* * *}(0.012)$ & $0.25^{* * *}(0.014)$ \\
\hline Log[Life] & $0.051^{* * *}(0.002)$ & $0.048^{* * *}(0.002)$ & $0.028^{* * *}(0.002)$ \\
\hline Log[Condition] & $0.18^{* * *}(0.01)$ & $0.14^{* * * *}(0.01)$ & $0.14^{* * *}(0.015)$ \\
\hline Log[Competitors] & $-0.002^{* * *}(0.0002)$ & $-0.002^{* * * *}(0.0002)$ & $-0.001^{* * * *}(0.0002)$ \\
\hline Log[Offer Position] & $-0.003^{* * *}(0.0001)$ & $-0.002^{* * *}(0.0001)$ & $-0.003^{* * *}(0.0001)$ \\
\hline $\mathrm{R}^{2}$ (with Fixed Effects) & 0.76 & 0.78 & 0.8 \\
\hline
\end{tabular}

Table A3: The dependent variable is Log of Sale Time. All models use OLS with product-seller fixed effects. Robust standard errors are in parenthesis. ${ }^{* * *}$ and $* *$ denote significance at $1 \%$ and $5 \%$, respectively.

Effect of Seller and Product Characteristics on Sale Time for Laptops

\begin{tabular}{|c|c|c|c|}
\hline Variable & Small Sellers & Medium Sellers & Large Sellers \\
\hline Log[Sale Price] & $0.035^{* * *}(0.001)$ & $0.029^{* * *}(0.001)$ & $0.038^{* * *}(0.001)$ \\
\hline Log[Seller Rating] & $0.67^{* * *}(0.01)$ & $0.75^{* * *}(0.01)$ & $0.56^{* * *}(0.01)$ \\
\hline Log[Life] & $0.12^{* * *}(0.001)$ & $0.15^{* * *}(0.001)$ & $0.07^{* * *}(0.001)$ \\
\hline Log[Condition] & $0.065^{* * *}(0.001)$ & $0.042^{* * *}(0.001)$ & $0.045^{* * *}(0.001)$ \\
\hline Log[Competitors] & $0.0005^{* *}(0.0003)$ & $0.001^{* *}(0.0003)$ & $0.001^{* *}(0.0003)$ \\
\hline Log[Offer Position] & $-0.001^{* * *}(0.0001)$ & $-0.001^{* * *}(0.0001)$ & $-0.001^{* * *}(0.0001)$ \\
\hline $\mathrm{R}^{2}$ & 0.72 & 0.81 & 0.74 \\
\hline
\end{tabular}

Table A4: The dependent variable is Log of Sale Time. All models use OLS with product-seller fixed effects. Robust standard errors are in parenthesis. ${ }^{* * *}$ and ${ }^{* *}$ denote significance at $1 \%$ and $5 \%$, respectively. 